\title{
Distribution System Voltage Performance Analysis for High-Penetration Photovoltaics
}

Subcontract Report NREL/SR-581-42298

February 2008

E. Liu and J. Bebic GE Global Research Niskayuna, New York

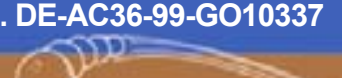




\section{Distribution System Voltage Performance Analysis for High-Penetration Photovoltaics}

E. Liu and J. Bebic

GE Global Research

Niskayuna, New York

NREL Technical Monitor: Ben Kroposki

Prepared under Subcontract No. ADC-7-77032-01

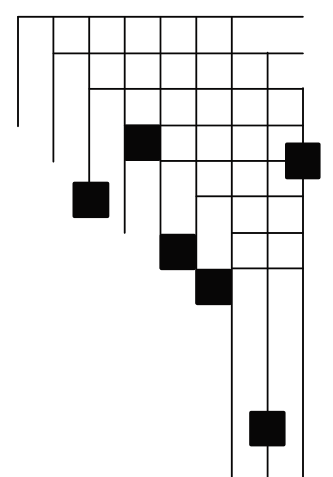




\section{NOTICE}

This report was prepared as an account of work sponsored by an agency of the United States government. Neither the United States government nor any agency thereof, nor any of their employees, makes any warranty, express or implied, or assumes any legal liability or responsibility for the accuracy, completeness, or usefulness of any information, apparatus, product, or process disclosed, or represents that its use would not infringe privately owned rights. Reference herein to any specific commercial product, process, or service by trade name, trademark, manufacturer, or otherwise does not necessarily constitute or imply its endorsement, recommendation, or favoring by the United States government or any agency thereof. The views and opinions of authors expressed herein do not necessarily state or reflect those of the United States government or any agency thereof.

Available electronically at http://www.osti.gov/bridge

Available for a processing fee to U.S. Department of Energy and its contractors, in paper, from:

U.S. Department of Energy

Office of Scientific and Technical Information

P.O. Box 62

Oak Ridge, TN 37831-0062

phone: 865.576 .8401

fax: 865.576 .5728

email: mailto:reports@adonis.osti.gov

Available for sale to the public, in paper, from:

U.S. Department of Commerce

National Technical Information Service

5285 Port Royal Road

Springfield, VA 22161

phone: 800.553 .6847

fax: 703.605.6900

email: orders@ntis.fedworld.gov

online ordering: http://www.ntis.gov/ordering.htm

This publication received minimal editorial review at NREL 


\section{Preface}

Now is the time to plan for the integration of significant quantities of distributed renewable energy into the electricity grid. Concerns about climate change, the adoption of state-level renewable portfolio standards and incentives, and accelerated cost reductions are driving steep growth in U.S. renewable energy technologies. The number of distributed solar photovoltaic (PV) installations, in particular, is growing rapidly. As distributed PV and other renewable energy technologies mature, they can provide a significant share of our nation's electricity demand. However, as their market share grows, concerns about potential impacts on the stability and operation of the electricity grid may create barriers to their future expansion.

To facilitate more extensive adoption of renewable distributed electric generation, the U.S. Department of Energy launched the Renewable Systems Interconnection (RSI) study during the spring of 2007. This study addresses the technical and analytical challenges that must be addressed to enable high penetration levels of distributed renewable energy technologies. Because integration-related issues at the distribution system are likely to emerge first for PV technology, the RSI study focuses on this area. A key goal of the RSI study is to identify the research and development needed to build the foundation for a high-penetration renewable energy future while enhancing the operation of the electricity grid.

The RSI study consists of 15 reports that address a variety of issues related to distributed systems technology development; advanced distribution systems integration; system-level tests and demonstrations; technical and market analysis; resource assessment; and codes, standards, and regulatory implementation. The RSI reports are:

- Renewable Systems Interconnection: Executive Summary

- Distributed Photovoltaic Systems Design and Technology Requirements

- Advanced Grid Planning and Operation

- Utility Models, Analysis, and Simulation Tools

- Cyber Security Analysis

- Power System Planning: Emerging Practices Suitable for Evaluating the Impact of High-Penetration Photovoltaics

- Distribution System Voltage Performance Analysis for High-Penetration Photovoltaics

- Enhanced Reliability of Photovoltaic Systems with Energy Storage and Controls

- Transmission System Performance Analysis for High-Penetration Photovoltaics

- Solar Resource Assessment

- Test and Demonstration Program Definition

- Photovoltaics Value Analysis

- Photovoltaics Business Models 
- Production Cost Modeling for High Levels of Photovoltaic Penetration

- Rooftop Photovoltaics Market Penetration Scenarios.

Addressing grid-integration issues is a necessary prerequisite for the long-term viability of the distributed renewable energy industry, in general, and the distributed PV industry, in particular. The RSI study is one step on this path. The Department of Energy is also working with stakeholders to develop a research and development plan aimed at making this vision a reality. 


\section{Acknowledgments}

Reigh Walling of Power Systems Energy Consulting pointed out a significant deficiency in the earlier version of this work. His firm grounding in reality and candid criticism are gratefully acknowledged. 


\section{Executive Summary}

Currently, electrical distribution systems are designed and operated based on the assumption of centralized generation, with the corollary that the power always flows from the distribution substation to the end-use customers. With the increasing penetration of residential and commercial PV, the PV power generation could not only offset the load, but could also cause reverse power flow through the distribution system. Significant reverse power flow may cause operational issues for the traditional distribution system, including:

- Over-voltage on the distribution feeder (loss of voltage regulation).

- Increased short circuit currents, potentially reaching damaging levels.

- Protection desensitization and potential breach of protection coordination.

- Incorrect operation of control equipment that may lead to an increase in the number of operations and related equipment wear, or to further aggravation of problems that affect more equipment and more customers.

Among all the potential problems that may be caused by the high penetration of PV, voltage regulation is the most likely one, because it is directly correlated to the amount of reverse power flow. This study was carried out to investigate the impact of different penetration levels of $\mathrm{PV}$ on the feeder voltage profile and on the equipment commonly used for feeder voltage regulation. The flow of reactive and active power on the feeder was investigated with different assumptions of inverter participation, and with various assumptions about the coordinated control of inverters and utility equipment.

A representative distribution feeder with a selection of typically used equipment was selected from a previous NREL study ${ }^{4}$. This feeder included commercial and residential loads. Tap-changing transformers and switched capacitors were applied at the substation and along the feeder. The model was further refined by explicitly representing the low voltage service transformers and the secondary circuits to which distributed PV generation is connected.

A series of case studies was conducted with different penetrations of PV, assuming several commonly used voltages regulation methods. The study results show:

- Reverse power flow at all studied PV penetration levels can be accommodated using traditional utility equipment with, perhaps, modified controls.

- Voltage rise on the secondary circuits is significant, and it should be included in the analysis. Establishing a communication link between service points (customer meter connections) and the utility equipment is helpful as it enables explicit control over the worst-case voltage.

In all the cases studied, PV inverters can positively contribute to feeder voltage regulation and result in an improved voltage profile. At a high enough penetration, PV inverters may be able to replace all voltage regulation equipment on a feeder. The study results show: 
- At a low PV penetration level (5\%), inverters do not make a significant impact on the feeder's voltage regulation during peak load.

- At a medium PV penetration level (10\%), inverter voltage support can help reduce the size of the voltage support capacitors by nearly $40 \%$.

- At high PV penetration levels (30\% - 50\%), PV inverters might entirely displace voltage support capacitors.

At higher penetration levels, inverter-coupled PV generation displaced some of the conventional generation. In order to match the performance of the inverters to that of conventional generators, inverters have to be able to exchange reactive power with the system. To allow for this, the following is needed:

- Current interconnection requirements need to be evolved.

- Inverter ratings need to be increased to allow for reactive power capability at all levels of power output. This can be stipulated by interconnection requirements or by carefully designed incentive programs.

- The operation of inverters has to be coordinated with the control of traditional voltage control equipment to take full advantage of the available reactive power capabilities of the inverters.

Recommendations for future research in this field are:

- Develop a set of recommended practices to reconcile existing feeder voltage control techniques with high penetrations of distributed PV. This work illustrates several such cases, but it is limited to one feeder topology. A more comprehensive coverage of feeder topologies would be beneficial.

- Develop a set of recommended practices for modeling PV inverters for load flow analysis and for other relevant planning purposes, such as short circuit current calculations. At the same time, expand the number of possible control options for traditional equipment in the analysis software. This would result in a more consistent understanding of the issues in the industry, and would simplify the test case setup so that it is possible to evaluate any specific situation.

- Create a set of benchmark cases to facilitate testing the models and the associated software. Some of the confusion and unwarranted concerns about the impact of PV generation may be a result of inconsistent and incorrect modeling.

- Develop automated screening tools that will enable evaluation of the impact of PV on the distribution system; all prospective installations could then be screened and only the ones requiring more detailed assessment would be floated up to the utilities. This would help preserve low installation costs while allowing for the more detailed assessment necessary at higher penetration levels of distributed PV. 
- Develop functional requirements for communication infrastructure that will enable the coordinated operation of all equipment on the distribution feeder. The same infrastructure can be used to enable demand side management, implementation of flexible metering tariffs, and enhanced distribution system management.

- Fund demonstration opportunities that illustrate feeder operation with significant PV penetration. 


\section{Table of Contents}

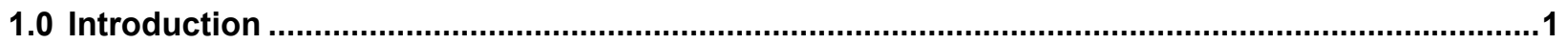

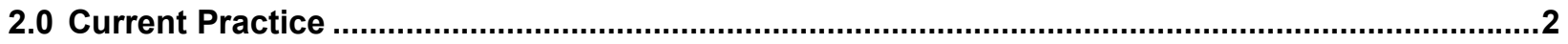

2.1 Distribution System Voltage Control Requirements ..................................................2

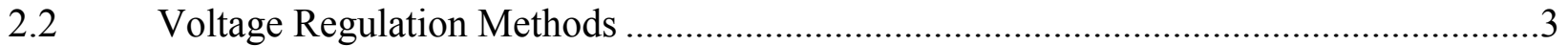

2.2.1 On-Load Tap-Changing (OLTC) Transformers / Voltage Regulators ......................4

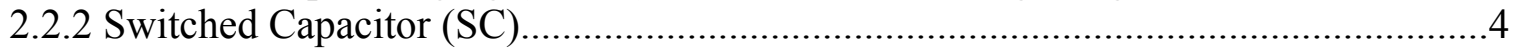

Inverters' Reactive Power Support ........................................................................5

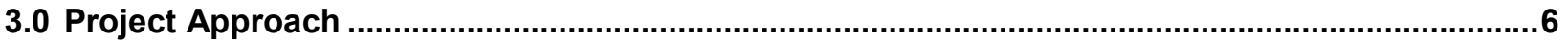

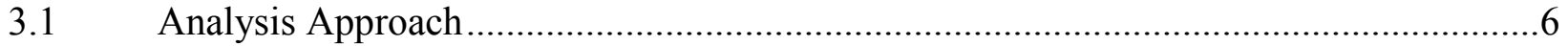

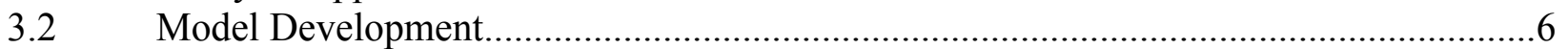

3.2.1 Distribution Feeder Model ...........................................................................6

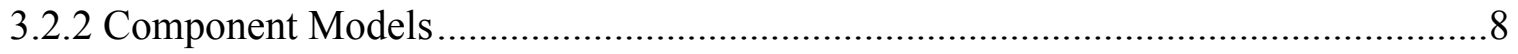

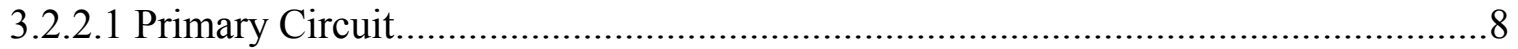

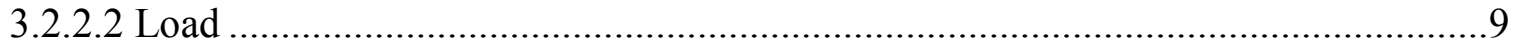

3.2.2.3 Secondary Circuit...................................................................................

3.2.2.4 Photovoltaic ............................................................................................ 9

3.2.2.5 PV inverter Reactive Power (VAR) Support .................................................9

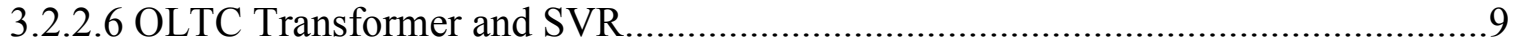

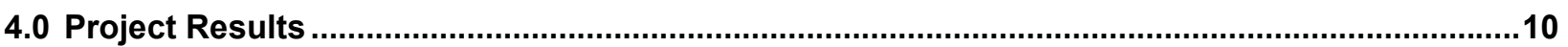

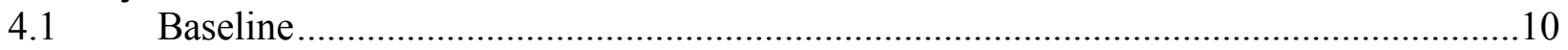

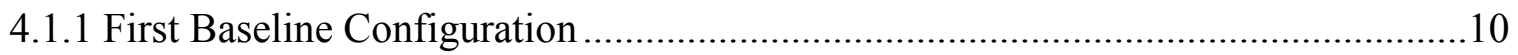

4.1.2 Second Baseline Configuration....................................................................... 12

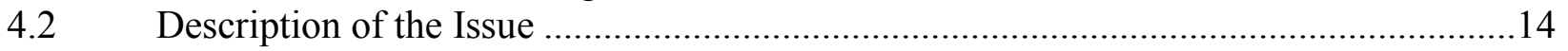

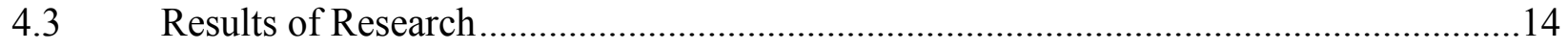

4.3.1 Assumptions About PV Inverter Capabilities.........................................................15

4.3.2 Peak Load, 5\%, 10\%, 30\% and 50\% Penetration, OLTC + SVR, Inverters

Supplying Reactive Power ............................................................................. 16

4.3.3 Peak Load, 50\% Penetration, OLTC, Inverters Supplying Reactive Power............21

4.3.4 Power Export, 50\% Penetration, OLTC, IEEE1547 Inverters................................22

4.3.5 Power Export, 50\% Penetration, OLTC, Inverters Controlling Feeder

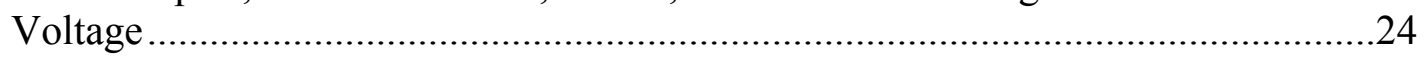

4.3.6 Power Export, 50\% Penetration, OLTC, Inverters Supplying Capacitive

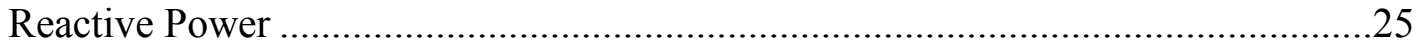

4.3.7 Power Export, 50\% Penetration, OLTC + SVR, Inverters Supplying Capacitive Reactive Power .................................................................................27

4.3.8 Power Export, 50\% Penetration, OLTC, Inverters Controlling Total Service

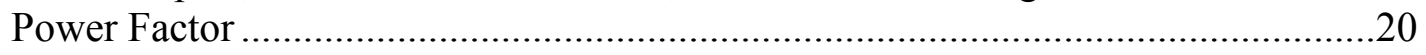

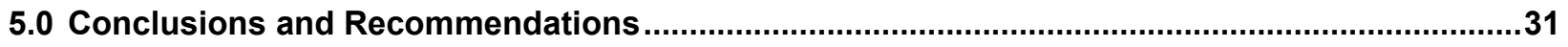

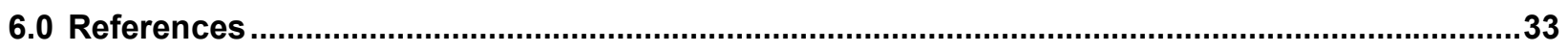

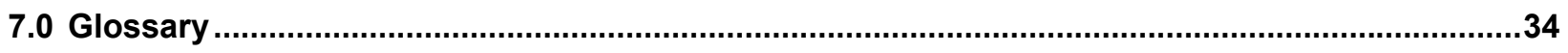




\section{List of Figures}

Figure 1. Voltage range limits used in this study according to $\mathrm{Willis}^{3}$........................................

Figure 2. Determining the inverter's reactive power limits .......................................................5

Figure 3. PSLF single line diagram of the distribution system model .........................................

Figure 4. Illustration of Feeder 2 in the distribution system model ...........................................

Figure 5. Baseline 1: voltage profile at peak load with the switched capacitor ..........................11

Figure 6. Baseline 1: power flow at peak load with the switched capacitor ..............................11

Figure 7. Baseline 2: voltage profile at peak load with SVR …………...................................12

Figure 8. Baseline 2: power flow at peak load with SVR ......................................................13

Figure 9. Relationship between inverter size and its reactive power capability .........................16

Figure 10. 5\% PV penetration voltage profile: peak load with SVR ........................................17

Figure 11. 5\% PV penetration power flow: peak load with SVR ............................................17

Figure 12. 10\% PV penetration voltage profile: peak load with SVR ........................................18

Figure 13. 10\% PV penetration power flow: peak load with SVR ……...................................18

Figure 14. 30\% PV penetration voltage profile: peak load with SVR ......................................19

Figure 15. 30\% PV penetration power flow: peak load with SVR ..........................................19

Figure 16. 50\% PV penetration voltage profile: peak load with SVR .........................................20

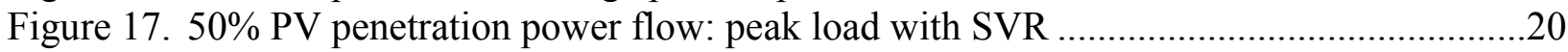

Figure 18. 50\% PV penetration voltage profile: peak load with inverter only .............................21

Figure 19. 50\% PV penetration power flow: peak load with inverters only ...............................22

Figure 20. 50\% PV penetration: voltage profile at max reverse power flow with OLTC ….........23

Figure 21. 50\% PV penetration: power flow at max reverse power flow with OLTC ..................23

Figure 22. 50\% PV penetration voltage profile: inverter voltage support ....................................24

Figure 23. 50\% PV penetration power flow: inverter voltage support .......................................25

Figure 24. 50\% PV penetration voltage profile: inverter VAR support........................................26

Figure 25. 50\% PV penetration power flow: inverter VAR support............................................27

Figure 26. 50\% PV penetration voltage profile: inverter VAR support with SVR.......................28

Figure 27. 50\% PV penetration power flow: inverter VAR support with SVR ............................28

Figure 28. 50\% PV penetration voltage profile: inverter power factor correction.........................29

Figure 29. 50\% PV penetration power flow: inverter power factor correction...............................30

\section{List of Tables}

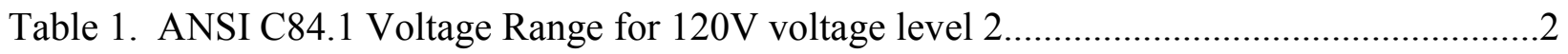

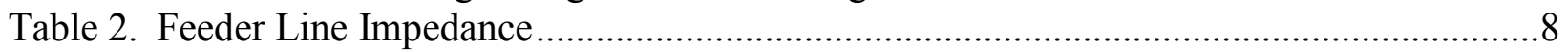

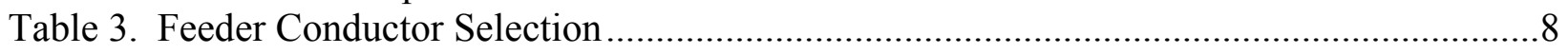

Table 4. Feeder Voltage Equipment ………………..........................................................

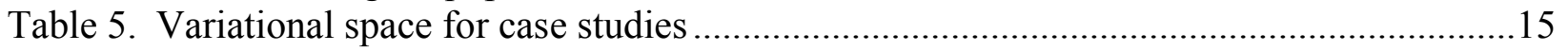

Table 6. Reduction in feeder losses due to inverter Q support relative to baseline configuration 2 


\subsection{Introduction}

Solar photovoltaics (PV) are among the fastest growing energy sources in the world, with annual growth rates of $25-35 \%$ over the last ten years. The markets for solar PV have undergone a dramatic shift in the last five years. Prior to 1999, the primary market for PV was in off-grid applications, such as rural electrification, water pumping, and telecommunications. However, now over $78 \%$ of the global market is for grid-connected applications where the power is fed into the electrical network ${ }^{1}$. Furthermore, most of the new PV capacity has been installed in the distribution grid as distributed generation. As the use of solar photovoltaics continues to expand, concern about its potential impact on the stability and operation of the electricity grid grow as well. Utilities and power system operators are preparing to integrate and manage more of this renewable electricity source in their systems.

This study assesses the effects of a high penetration of distributed PV on the distribution system voltage control, and on the associated reactive power flow through the distribution system. A representative distribution system feeder that includes both residential and commercial content was selected from a previous study ${ }^{4}$. The selected feeder also includes voltage control equipment such as switched capacitors and on-load tap-changing transformers. The model was further expanded to represent service transformers and secondary circuits at the point of service entrance (the customer meter) - the likely connection point of the PV inverter.

The report is organized as follows. In Section 2, the current practices used for distribution voltage regulation are summarized, and the technical capabilities of inverters relevant to feeder voltage control are presented. Section 3 introduces the analysis approach, discusses modeling requirements, and presents the models used. Section 4 presents the study results; it includes establishing the baseline and analyzes the impact of the different PV penetration scenarios (i.e., $5 \%, 10 \%, 30 \%$, and $50 \%$ ) on the feeder voltage profile. It also illustrates how the reverse power flow on the distribution feeder impacts the operation of voltage regulation devices such as the on-load tap-changing transformer. Case results exploring different voltage control options are presented and discussed. Reactive power flow through the feeder is also analyzed using different assumptions for inverter participation and for the coordination of inverter and feeder control. The study is summarized in Section 5. Future research needs to explore the opportunity for optimal distribution system design for high penetration of PV are also identified. 


\subsection{Current Practice}

\subsection{Distribution System Voltage Control Requirements}

Voltage regulation is an important subject in electrical distribution engineering, because it is the utility's responsibility to keep the customers' service voltage (the voltage at the customer's meter, or the load side of the point of common coupling (PCC)) within the acceptable range. ANSI C 84.1 specifies a guideline for this range, but the utilities have the freedom to specify it differently based on their specific circumstances. ANSI C84.1 also specifies utilization voltage, which refers to the voltage at the point of use where the outlet equipment is plugged in. Furthermore, two ranges are defined: Range A is recommended for normal operating conditions, while Range B corresponds to unusual conditions, during which the occurrence has to be limited in time duration and frequency. Recommended service and utilization voltage limits according to ANSI C84.1 are shown in Table 1. Utilities are generally concerned with maintaining the service voltage within acceptable limits; the utilization voltage then follows automatically, provided that the house wiring is done according to building codes.

Table 1. ANSI C84.1 Voltage Range for $120 \mathrm{~V}_{\text {voltage level }}{ }^{2}$

\begin{tabular}{|l|c|c|c|c|}
\hline & \multicolumn{2}{|c|}{ Service } & \multicolumn{2}{c|}{ Utilization } \\
\hline & Min & Max & Min & Max \\
\hline $\begin{array}{l}\text { Range A } \\
\text { (Normal) }\end{array}$ & $-5 \%$ & $+5 \%$ & $-8.3 \%$ & $+4.2 \%$ \\
\hline $\begin{array}{l}\text { Range B } \\
\text { (Emergency) }\end{array}$ & $-8.3 \%$ & $+5.8 \%$ & $-11.7 \%$ & $+5.8 \%$ \\
\hline
\end{tabular}

Irrespective of actual adopted voltage limits (by ANSI C 84.1 or by the individual utility), most utilities control the service voltage indirectly by controlling the voltage on the primary circuit, the feeder. Service voltage is directly dependent on feeder voltage; when considered on the same voltage base, service voltage is equal to the feeder voltage minus the voltage drop across the service transformer and the secondary circuit connection. Consequently, it is possible to predict the service voltage based on the feeder voltage as long as the service transformer and service runs have consistent parameters for all loads. Utilities capitalize on this fact and develop internal design guidelines for sizing service transformers and for deciding the size and length of a service connection. Following the guidelines then enables them to eliminate the need to record the data related to the secondary circuits, resulting in a substantial saving in database size. (Admittedly, database size is not a significant factor nowadays, but these practices were developed more than 50 years ago when computer resources were scarce.) Hence, with design guidelines in place, service voltage is controlled indirectly by controlling the feeder voltage. 
Figure 1 shows an example of voltage limits for the primary circuit, the service entrance, and utilization based on one utility's guidelines ${ }^{3}$. It reflects the adjustment for assumptions about additional voltage drop in the secondary circuit and allows for the necessary margin. In this study, the primary voltage and service entrance voltage limits shown in Figure 1 were used as target limits.

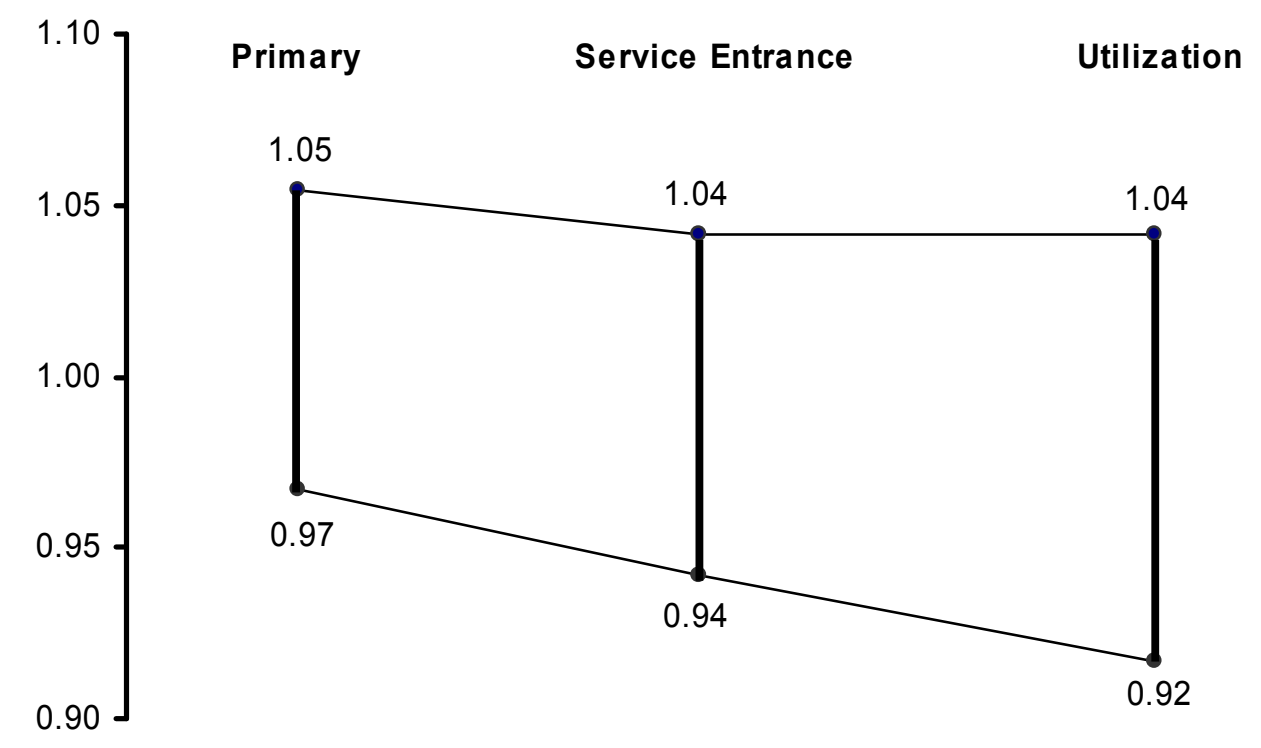

Figure 1. Voltage range limits used in this study according to Willis ${ }^{3}$

\subsection{Voltage Regulation Methods}

The voltage regulation practice applied to distribution systems is based on the radial power flow from the substation to the load. Voltage drop along the distribution feeder is inevitable and it is, in fact, required in order to move power from the substation to the customers. Typically, two (boundary) operating conditions of the feeder are considered: feeder voltage should not drop below the minimum during peak load condition, and it should not exceed the maximum during light load condition.

Voltage drop on the feeder is a consequence of current flow and the impedance (resistance and reactance) of the feeder conductor, transformer, and load. Loads require active and reactive power, and the related current that supplies the active and reactive power causes the voltage drop on feeder conductors. Feeder conductors are a given (they are selected first, based on economic considerations ${ }^{*}$ ). With conductor sizes known (i.e., their circuit parameters are fixed), there are two fundamental ways to control the voltage on the feeder: by using on-load tap-changing transformers, or by installing fixed or switched capacitors to offset the reactive power demand from the load and thus reduce

\footnotetext{
* Larger conductors have lower voltage drop and lower power losses, but they also cost more, so there is a tradeoff between savings due to lowered losses and increased costs of the conductors. Utilities commonly have design guidelines that are based on underlying economic consideration, practicality of carrying varying sizes of conductors in stock, and other considerations such as feeder pick up from an adjacent substation for increased reliability.
} 
the current flow through the feeder and the related voltage drop. These two methods are discussed in more detail next.

\subsubsection{On-Load Tap-Changing (OLTC) Transformers / Voltage Regulators}

The on-load tap-changing transformer (OLTC), or voltage regulator, is an essential part of a distribution network. Automatically adjustable OLTCs are commonly used at distribution substations to raise the starting voltage for a feeder under load, so that some point along the feeder has a desired voltage. The adjustment is proportional to the load, so this practice works well for all anticipated loading conditions. This control strategy is referred to as the "line drop compensation." The amount of permissible voltage increase is limited if there is a load (customer) near the voltage regulator, so in some cases additional voltage regulators along the feeder run might be necessary.

Voltage regulators, or OLTCs, are typically constructed as autotransformers with automatically adjusting taps. The controls measure the voltage and load current, estimate the voltage at the remote (controlled voltage) point, and trigger the tap change when the estimated voltage is out of bounds. Multiple tap change actions may be performed until the voltage is brought within bounds. The taps typically provide a range of $\pm 10 \%$ of transformer rated voltage with 32 steps. Each step of voltage is therefore $0.625 \%$ of the rated voltage. $^{2}$

\subsubsection{Switched Capacitor}

It was already explained that loads require active and reactive power, and that the related current causes the voltage drop on feeder conductors. The load's reactive power demand can either be supplied from the substation or by inserting capacitor banks along the feeder. The reactive power supplied by the capacitor banks offsets the reactive power of the load and consequently reduces the amount that needs to come from the substation and the associated voltage drop. The capacitor banks can be fixed (permanently connected) or switched (connected when needed), so that their supplied reactive power matches the need of the load. In practical installations this matching is seldom perfect, because the load and its reactive power demand vary continuously while the capacitor banks are switched in chunks. Moreover, the reactive power from capacitors varies with voltage squared, and drops off at low voltages when it is most needed. Overcompensation of the feeder (associated with too much capacitance) leads to voltage rise on the feeder, and it might require the voltage regulator in the substation to take action to lower the voltage to accommodate the rise due to overcompensation by the capacitors.

The controls used for switching capacitor banks can be based on: a time clock (load is correlated with time of day); the temperature (heavy load such as air-conditioning is correlated with ambient temperature); the voltage (low feeder voltage is an indication of the heavy load); the reactive power flow (to balance the reactive power actually drawn by the load); or the feeder current (similar to reactive power control, but less expensive to implement) $)^{2}$. 


\subsection{Inverters' Reactive Power Support}

Currently, standards such as IEEE $1547^{\dagger}$ and UL1741 state that the PV inverter "shall not actively regulate the voltage at the PCC." Therefore, PV systems are designed to operate at unity power factor (i.e., they provide only active power) because this condition will produce the most real power and energy. This limitation is a matter of agreement, not a technical one; many inverters have the capability of providing reactive power to the grid in addition to the active power generated by their PV cells. This is illustrated in Figure 2. The inverter's ratings are represented by a vector with magnitude $S$; the semicircle with radius $\mathrm{S}$ denotes the boundary of the inverter's feasible operating range in $P Q$ space. Assuming that the power produced by PV array is $P_{p v}$, the feasible operating space reduces to the red line denoted by $P_{p v}$ or, more precisely, to the segment of the red line delimited by its intersection points with the semicircle. Reactive power $(Q)$ limits are then found by projecting the end points of the segment down to the Q axis; the values are labeled - $Q_{\text {limit }}$ and $Q_{\text {limit }}$. It follows that the inverter can supply positive and negative reactive power, that is, it can behave as both an inductor and a capacitor. The advantage of an inverter relative to a fixed capacitor is that it can vary the supplied reactive power continuously. The amount of $Q$ available from the inverter depends on its ratings $(S)$ and the active power supplied by the PV array. Consequently, the inverter can use its entire rating to supply $Q$ if $P_{p v}$ equals zero (there is no sun), and at the other extreme, it has no $Q$ capability if $P_{p v}$ equals $S$. Some $Q$ capability can always be retained by over-sizing the inverter; this will be discussed in a later section. Note that this is for a unidirectional gridconnected PV inverter. Inverters connected to energy storage may allow for full fourquadrant charging and discharging of real and reactive power. In addition to the continuous reactive power support, inverters can operate very fast (milliseconds to microseconds with high switching frequency inverters) in comparison with capacitors, which can cause switching transients.

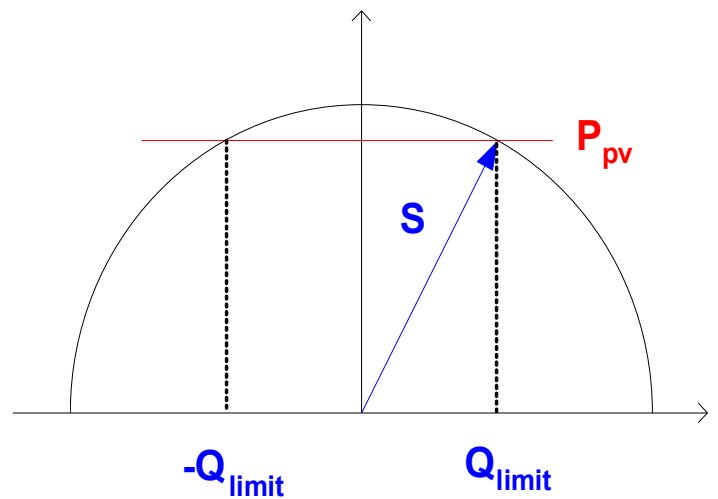

Figure 2. Determining the inverter's reactive power limits

A number of publications are available that address the benefits of using inverter-based distributed generation for voltage support, their challenges, and their potential solutions. ${ }^{8,9}$

\footnotetext{
${ }^{\dagger}$ IEEE 1547 Standard for Interconnecting Distributed Resources with Electric Power Systems, 2003.
} 


\subsection{Project Approach}

\subsection{Analysis Approach}

The approach used in this study involves the following procedure:

1. Select and model a representative distribution feeder with various typical voltage support equipment.

2. Refine the model by adding a low-voltage service transformer and a secondary circuit.

3. Conduct load flow simulation of various scenarios, including peak load and various PV penetrations with maximum reverse power flow.

4. Review feeder voltage profile, the active and reactive power flows, and the impact of various control configurations.

\subsection{Model Development}

A representative distribution system was based on a previous distributed generation study conducted by General Electric under the contract with NREL ${ }^{4}$. The selected system includes the most commonly used distribution system components that are important for investigation of voltage regulation; there are voltage regulators at the substation and along the feeder, switched capacitors, and distribution transformers. In order to explicitly investigate the voltage at the customer service entrance service transformers and secondary circuits were added to the original model. The model is suitable for examination of equipment interaction and the impact on the feeder voltage profile at different PV penetration levels. The details of the feeder and the component models are introduced in the following sections.

\subsubsection{Distribution Feeder Model}

The selected distribution system was modeled in PSLF ${ }^{10}$. A one-line diagram of the feeder as modeled in PSLF is shown in Figure 3. The assumptions are:

- The considered distribution system is radial and supplied by a medium-voltage transformer equipped with a tap changer;

- The distribution system includes two main feeders with laterals and distributed loads;

- Distribution substation protections allow active and reactive power back feed;

- Each load bus has a PV connected to it, with the size relative to the size of the load on the same bus;

- All the load buses are modeled as PQ buses;

- The system base is 10 MVA;

- Bus 999 represents the infinite bus and is the slack bus in the power flow model;

- A loop, shown as a dashed connection between buses 108 and 208, can be closed to link the two feeders. However, for this study, the loop is not connected. 


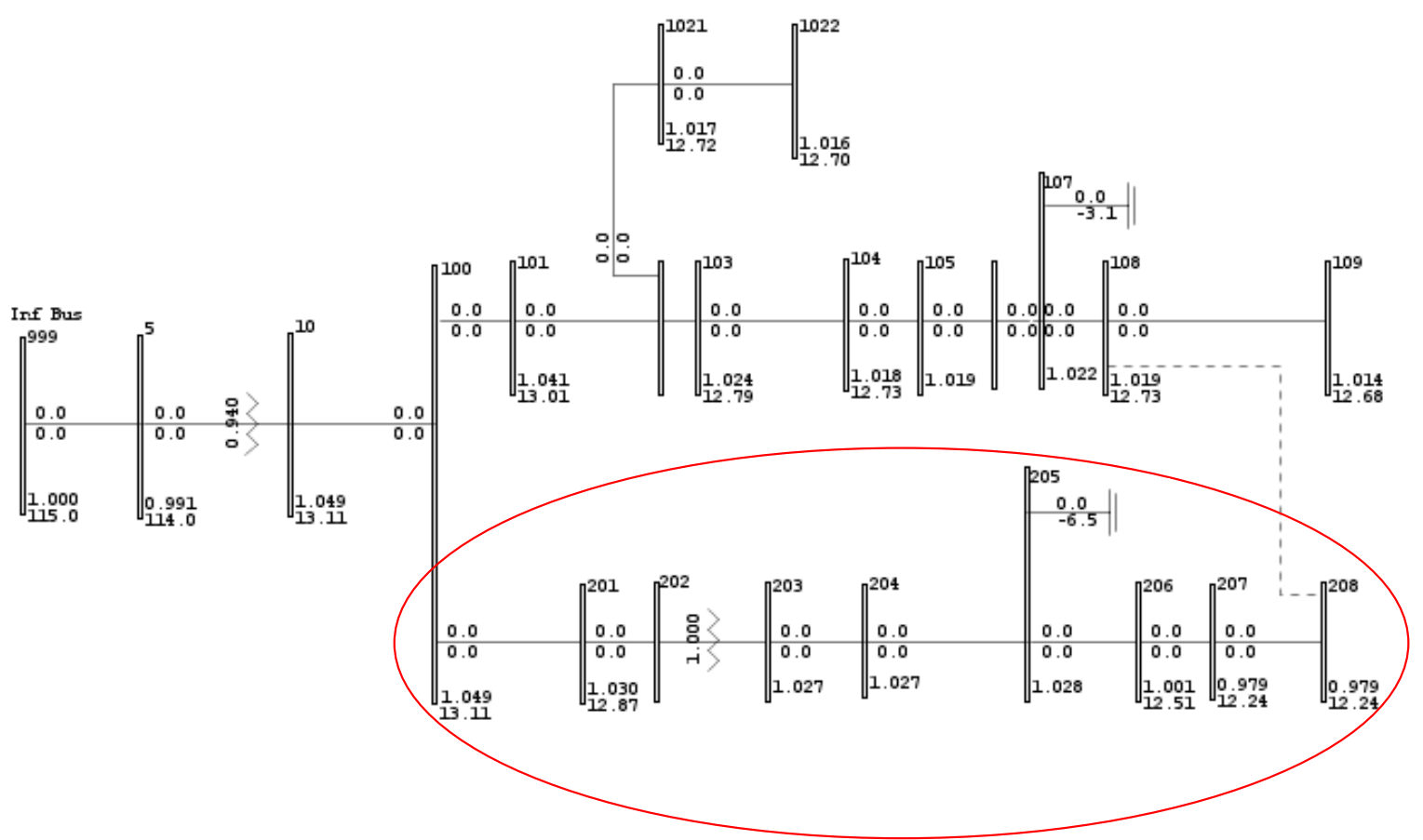

Figure 3. PSLF single line diagram of the distribution system model

Although the entire system was modeled and analyzed, only the results from Feeder 2 (circled in red in Figure 3), which includes all the interested voltage regulation devices, are illustrated in this report. Feeder 2 is described below.

- It is about six miles in length.

- Seven aggregated loads represent a mixture of residential load and commercial loads ranging from $0.3 \mathrm{MW}$ to $5 \mathrm{MW}$. The total load is $11 \mathrm{MVA}$.

- The primary feeder voltage is $12.5 \mathrm{kV}$. The secondary voltages are $240 \mathrm{~V}$ for residential loads and $600 \mathrm{~V}$ for commercial loads.

- A switched capacitor is located at about 4.6 miles from the substation, at bus 205.

- Two voltage regulators are employed - one in the substation and another at 2.6 miles from the substation, between buses 202 and 203. These two devices have similar characteristics, but they are purposely labeled differently to simplify notation in the following figures and text. The voltage regulator at the substation is referred to as the on-load tap changer, abbreviated as OLTC, and the one along the feeder is called the step voltage regulator, abbreviated as SVR.

Figure 4 shows an illustrative one-line diagram of Feeder 2. 


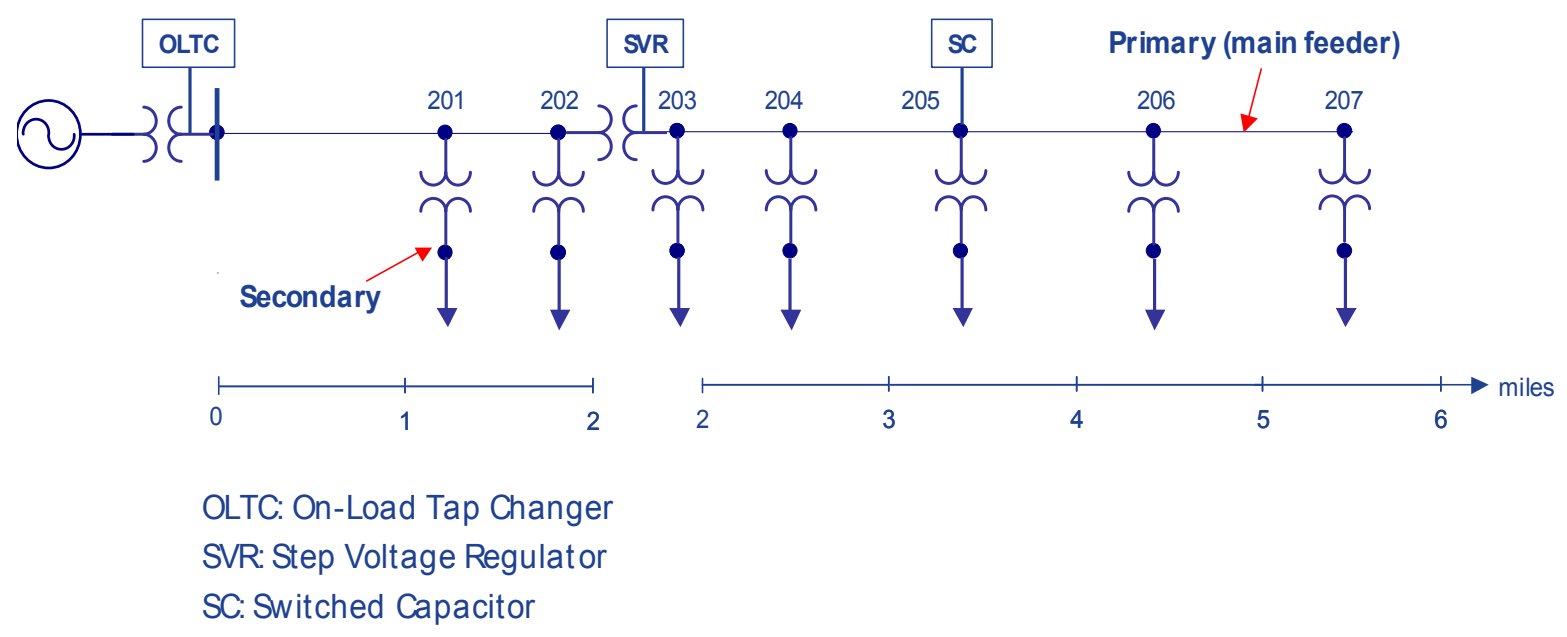

Figure 4. Illustration of Feeder 2 in the distribution system model

\subsubsection{Component Models}

In this section, the models of the major components used in the study feeder are introduced.

\subsubsection{Primary Circuit}

Table 2. Feeder Line Impedance

\begin{tabular}{|c|c|c|c|c|}
\hline From & To & Length (mile) & Conductor & X/R \\
\hline 100 & 201 & 1.3 & $Z 1$ & 2 \\
\hline 201 & 202 & 0.65 & $Z 1$ & 2 \\
\hline 203 & 204 & 0.65 & $Z 1$ & 2 \\
\hline 204 & 205 & 0.97 & $Z 1$ & 2 \\
\hline 205 & 206 & 1.1 & $Z 2$ & 2 \\
\hline 206 & 207 & 1.1 & $Z 2$ & 2 \\
\hline
\end{tabular}

Table 3. Feeder Conductor Selection

\begin{tabular}{|l|l|l|}
\hline Z1 & $0.648 \mathrm{Ohm} / \mathrm{mile}$ & ACSR 556.6 18/1 \\
\hline Z2 & $0.768 \mathrm{Ohm} / \mathrm{mile}$ & ACSR 266.8 18/2 \\
\hline
\end{tabular}

Table 4. Feeder Voltage Equipment

\begin{tabular}{|l|c|c|c|}
\hline \multicolumn{1}{|c|}{ Type } & From & To & Rating \\
\hline Transformer & 5 & 100 & 20 MVA \\
\hline SVR & 202 & 203 & 10 MVA \\
\hline $\begin{array}{l}\text { switched capacitor } \\
\text { (baseline 1) }\end{array}$ & 205 & & 6.2 MVAr \\
\hline $\begin{array}{l}\text { switched capacitor } \\
\text { (baseline 2) }\end{array}$ & 205 & & $2.5 \mathrm{MVAr}$ \\
\hline
\end{tabular}




\subsubsection{Load}

Loads were modeled as a combination of $40 \%$ constant power (active and reactive) load, and $60 \%$ of constant impedance load ${ }^{3}$. The loads in the study feeder have the power factor of 0.92 , which is representative of the mixture of residential and commercial loads.

\subsubsection{Secondary Circuit}

In order to investigate the voltage performance at the customer service entrance the secondary circuit, including the low voltage service transformers and the service feeder, were added to the original feeder model.

The service transformers are rated at 1.5 pu relative to the load they serve, with an impedance of $2.5 \%{ }^{2}$ and an $\mathrm{X} / \mathrm{R}$ ratio of 1.5 . The service feeders are typically 50 feet to 600 feet in length ${ }^{3}$. For this study, an average 200 -foot feeder length was selected. The impedance for the secondary feeder is calculated based on the conductor with 200 amps of thermal capacity. To simplify the model the impedance of the service transformer and the secondary feeder are added together and represented by the transformer impedance.

\subsubsection{Photovoltaics}

Grid-connected PV systems are designed to inject all of the real power produced by PV modules; they control the power precisely regardless of the voltage level, so they are best represented as negative constant power loads. The size of the negative PV load is defined proportional to the actual load connected at the same bus, based on the penetration level.

\subsubsection{PV inverter Reactive Power (VAR) Support}

The PV inverter model is not readily available in PSLF. To represent the reactive power capability of the inverters additional devices called Static VAR Devices (SVD), which are available in the PSLF standard library, were used. In PSLF, SVDs can be configured as switched or continuously controlled shunt elements whose admittance is adjusted in order to regulate the voltage at a specified bus. For the purpose of this analysis, the continuously controlled SVD model connected at each PV bus was used to simulate the VAR support feature of the PV inverter.

Each SVD is given the reactive power limits to represent the VAR support capability of the PV inverter at a studied condition. As was discussed in reference to Figure 2, the reactive power capability is decided by the size of the PV inverter $S$, and the active power output $P_{p v}$.

\subsubsection{OLTC Transformer and SVR}

The OLTC transformer and the SVR are modeled as tap-changing transformers that monitor the voltage at a remote bus and regulate the voltage to the defined limits by changing the turn ratio of the transformer. The tap range is $\pm 10 \%$ of rated and the step voltage is $0.625 \%$. The controlled bus depends on the case studied and will be defined in the specific case discussion. 


\subsection{Project Results}

In this section, the results obtained for different steady state conditions on the feeder are presented. Cases include different PV penetration scenarios combined with different control configurations. First is a review of the baseline conditions - a feeder under the peak load.

\subsection{Baseline}

In normal operating conditions the feeder voltage decreases as the distance from the distribution substation increases, and it may become lower than the voltage specified by the utility's guidelines. Two feeder configurations are reviewed for peak load, which were chosen because of the different $\mathrm{Q}$ (reactive power) profiles on the distribution feeder, with different voltage regulation devices and locations.

\subsubsection{First Baseline Configuration}

In the first baseline configuration, the OLTC regulates the service voltage of the last bus on the feeder to the voltage limits. A capacitor bank is used during peak load conditions to inject capacitive reactive power and to boost the voltage along the feeder. As shown in Figure 5, the combined action of the OLTC and the switched capacitor ensures that the voltages of all the buses at the primary feeder and the service entrances are within the specified limits. OLTC action shifts the entire curve up or down, while the switched capacitor raises the voltage at its bus.

The corresponding $\mathrm{P}$ and $\mathrm{Q}$ flow on the feeder is shown in Figure 6. P is fed from the substation to the load; the step curve begins at approximately $11 \mathrm{MW}$, then steps down to $\sim 9 \mathrm{MW}$ at the first load bus, indicating that the load at this bus is $\sim 2 \mathrm{MW}$. The P curve is characterized by a soft negative derivative between steps; this is representative of losses on the corresponding feeder segment. The Q curve, on the other hand, starts negative at the substation, indicating that the feeder is overcompensated by the switched capacitor; capacitive reactive power is delivered to the grid from this feeder. This is not an indication of a problem. It is a peculiar feature of this operating point. The steps in the $\mathrm{Q}$ curve are representative of reactive power consumption by the loads, which are generally inductive, resulting in negative steps. The sudden jump in $Q$ at the switched capacitor bus shows the contribution of the switched capacitor. It overpowers the inductive consumption of the load at the switched capacitor bus and results in a net Q increase of more than 5 MVAr. Past this point, Q is consumed at load nodes; approximately $2 \mathrm{MVAr}$ are drawn by the load at the end of the feeder. 


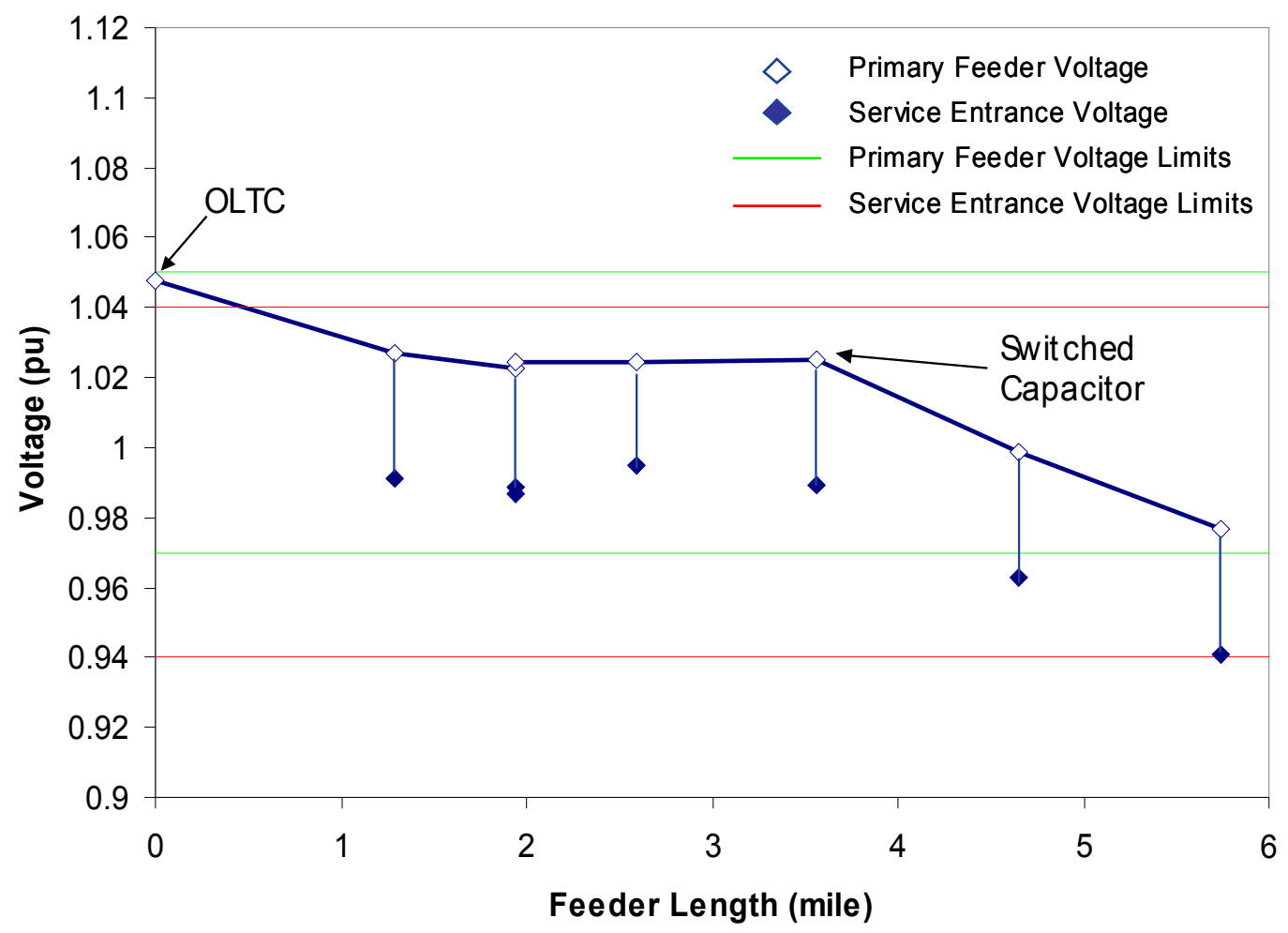

Figure 5. Baseline 1: voltage profile at peak load with the switched capacitor

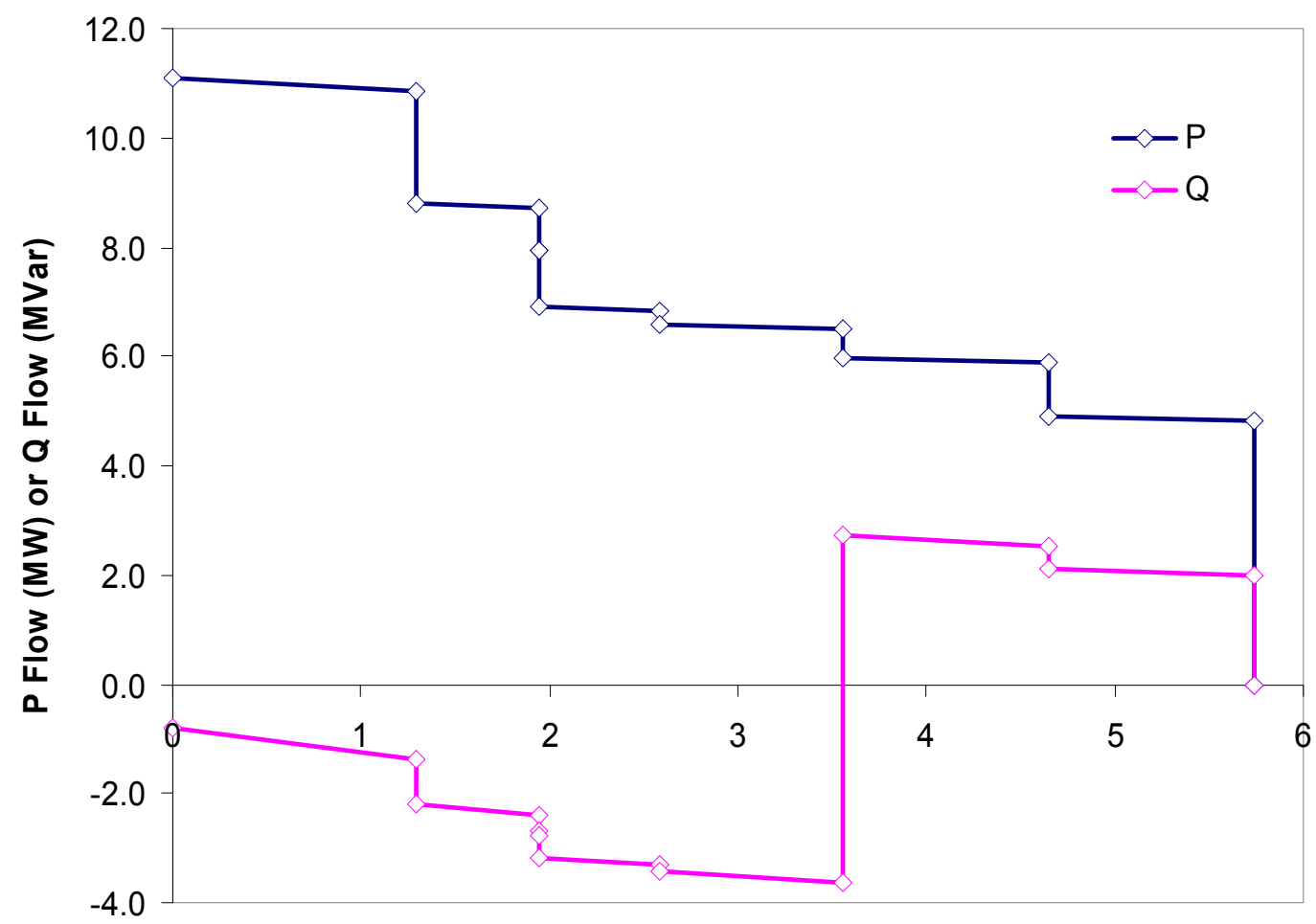

Feeder Length (mile)

Figure 6. Baseline 1: power flow at peak load with the switched capacitor 


\subsubsection{Second Baseline Configuration}

The second baseline configuration demonstrates the operation of SVR. The voltage regulation capability of SVR is constrained by the autotransformer tap limits; $\pm 10 \%$ was used. These limits may result in the need to combine SVR with other equipment, which was the case in this example. Hence, SVR is used along with the OLTC and the switched capacitor as follows. The OLTC regulates the primary side of the SVR, the SVR regulates the service voltage at the last load bus, and the switched capacitor is switched in to offset the reactive power consumption of the load along the feeder. The corresponding voltage profile is shown in Figure 7. At the discontinuity, where a step change in voltage occurs at the node with the SVR, the voltage is "stepped up." The contribution of the switched capacitor is analogous to the one in the first baseline configuration, but the capacitor is smaller, as will be discussed next.

The $\mathrm{P}$ and $\mathrm{Q}$ flows corresponding to the second configuration are shown in Figure 8. The $\mathrm{P}$ flow matches the one before, so it does not need additional discussion. However, the $\mathrm{Q}$ flow is markedly different. In this configuration, reactive power flows from the substation into the feeder, and it gets used up gradually at each load point. There is also a noticeable Q loss across the SVR. The SVR is the transformer, and reactive power is consumed on its leakage impedance. Reactive power injection by the switched capacitor is evident from the Q jump at the switched capacitor bus, but in this case net Q injection is less than 3 MVAr, compared with over 5 MVAr in the first configuration.

Both baseline configurations result in the feeder and service voltages being within the limits, but the underlying circuit behavior is quite different as is apparent from the above discussion. 


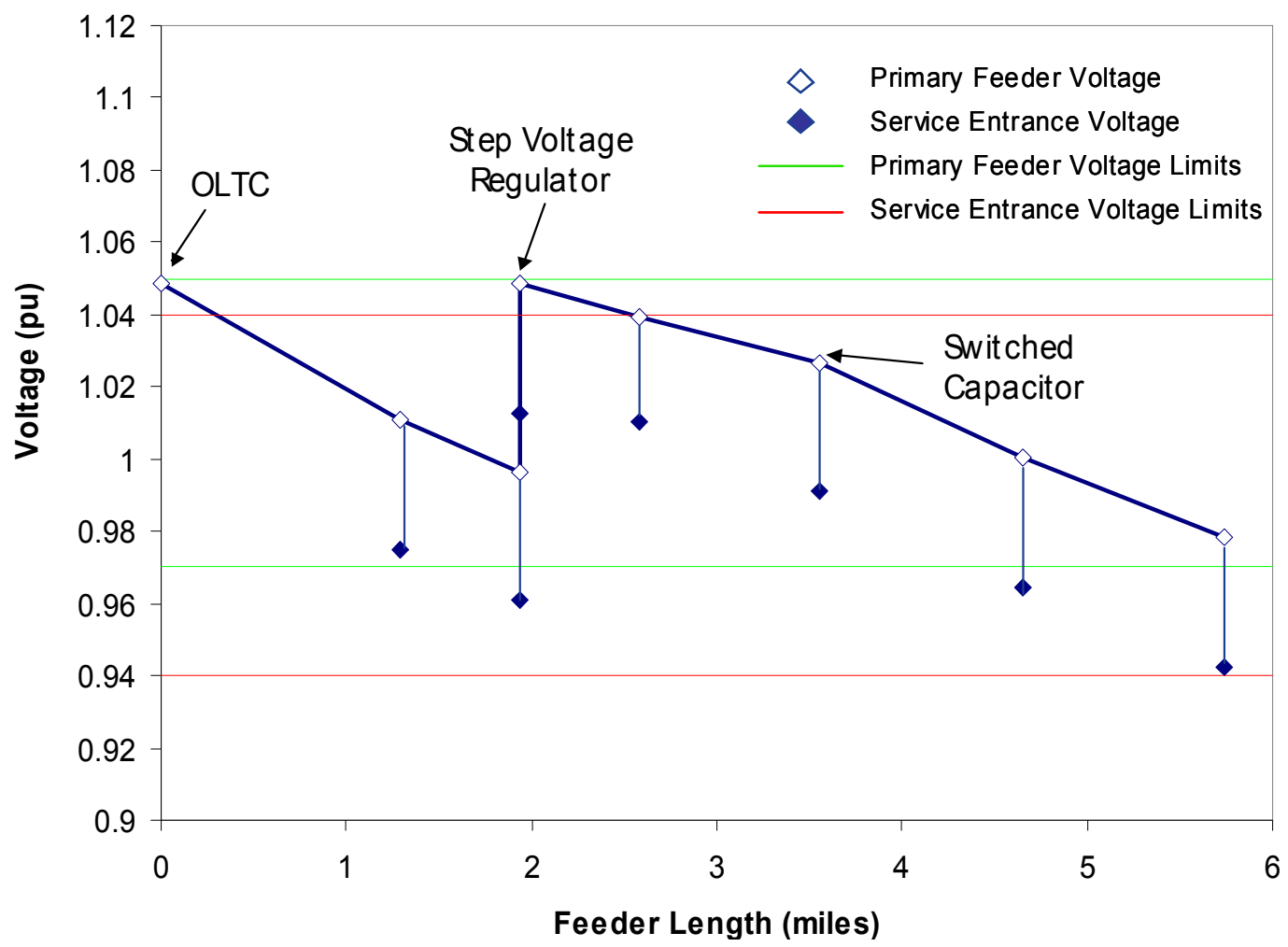

Figure 7. Baseline 2: voltage profile at peak load with SVR

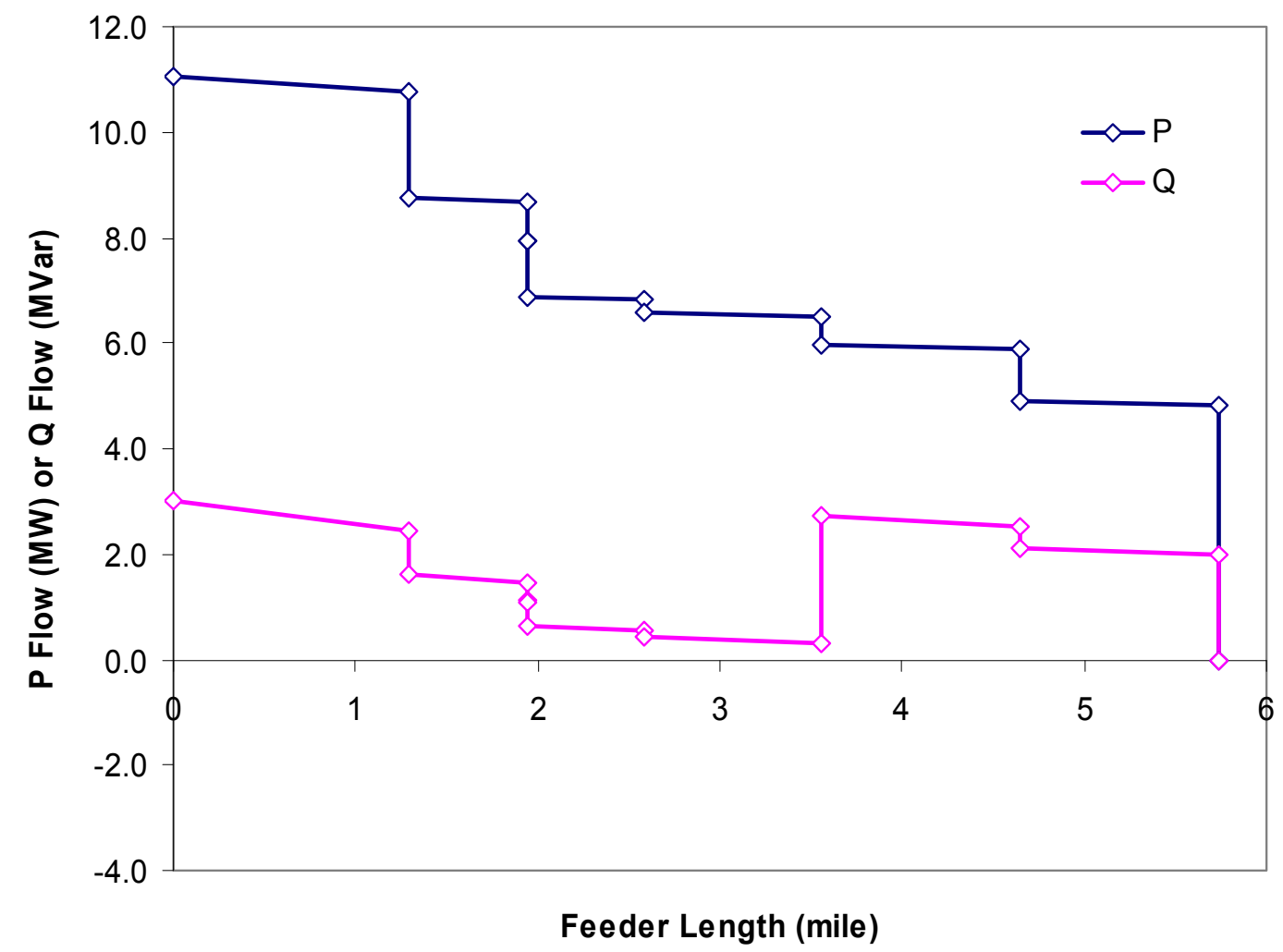

Figure 8. Baseline 2: power flow at peak load with SVR 


\subsection{Description of the Issue}

Introducing PV at the load side reduces the load demand and in turn leads to reduced losses and improved voltage profiles on the feeder. This is a fair observation as long as the PV generation coincides with the substantial load demand so that the net power flow remains from the substation to the load. As the penetration levels of PV rise, there may be time periods during the day when the net power flow is from the load (distributed PV) towards the substation - a situation not normally anticipated in the distribution system design. To illustrate this condition, consider a predominantly residential area with a significant penetration of PV. PV production is generally at its optimum at approximately 11 a.m., which is generally a period of light load condition, so power export through the distribution feeder and the substation back to the system becomes possible.

The associated reverse power flow tends to raise the voltage on the distribution feeder. The two presented base cases demonstrate that voltage drop drives power flow, so if the power flow reverses, the voltage slope will reverse as well. The obvious questions then are: will this situation cause problems, and how will the distribution circuit behave under these conditions?

These issues are discussed at various levels of PV penetration, combined with different assumptions about feeder equipment and different roles for inverters in feeder voltage control. To reduce data requirements the assumption was made that feeder load is zero during PV generation. This may appear unrealistic, but it is a matter of defining penetration. Assuming that $5 \%$ penetration causes $5 \%$ power export is equivalent to assuming that $10 \%$ penetration, combined with $5 \%$ load, results in a net export of $5 \%$. Although estimating feeder load during optimal insolation (peak PV production) would require significant data gathering, this assumption, while arguably incorrect, is pessimistic relative to the study of the feeder voltage profile. It results in worse voltage conditions.

\subsection{Results of the Research}

As indicated in Table 5, there are many possible variations of options for analyzing feeder voltage control. The full set of variations includes 192 cases, but not all combinations are meaningful. For example, it does not make sense to combine reverse power flow with reactive compensation using the switched capacitor, as it would lead to voltage problems. The number of options was carefully reduced to include "only" 56 cases that were then set up and evaluated. However, presenting all these results does not add value, as the conclusions often repeat between similar cases. The report was therefore reduced to the following cases.

Peak load cases are presented first under assumptions of different PV penetration using the inverters for reactive power support - beyond their current role prescribed by IEEE 1547. After that, reverse power flow on the feeder for $50 \% \mathrm{PV}$ penetration is presented by combining two options of voltage regulators with four options of inverter participation.

Since the role of the inverter is crucial for this discussion, assumptions about inverter capabilities are defined first in the next section. 
Table 5. Variational space for case studies

\begin{tabular}{|l|l|l|}
\hline Variable & Range & $\begin{array}{l}\text { Number of } \\
\text { options }\end{array}$ \\
\hline PV penetration & $5,10,30,50 \%$ & 4 \\
\hline Feeder load & $0,100 \%$ & 2 \\
\hline PV inverter participation & $\begin{array}{l}\text { IEEE 1547, voltage control, max Q, PF } \\
\text { control }\end{array}$ & 4 \\
\hline Voltage regulators & OLTC, OLTC + SVR, & 2 \\
\hline Switched capacitor & 0, base line 1, base line 2 & 3 \\
\hline
\end{tabular}

\subsubsection{Assumptions About PV Inverter Capabilities}

As discussed in Section 2.3, inverters have the capability to supply inductive and capacitive reactive power to the grid, and this ability is limited only by their ratings ${ }^{\ddagger}$. At the present time, inverters are not allowed to provide reactive power, so the manufacturers select their ratings to be equal to the maximum production of the connected PV modules. In terms of our previous discussion, $S=P_{P V \max }$. On the other hand, when $P_{P V}=0$ (no sun) the entire inverter capacity can be dedicated to reactive power support at essentially no extra cost, so it is often argued that the standards should evolve to allow reactive power support. Evolution of standards will be required at higher levels of PV penetration, so it is logical to assume that inverters could be allowed to provide reactive power to regulate voltage. Other questions also emerge. Most notably, how should this capability be used during maximum power production, and what is the reasonable increase in ratings to provide reactive power support?

To provide reactive power injection while supplying maximum active power from $\mathrm{PV}$ modules, it is necessary to increase the inverter size. Figure 9 illustrates the active and reactive power capability of the inverter versus the size. As shown in the figure, by increasing the inverter size by $10 \%$, making $\mathrm{S}=1.1 \mathrm{P}_{\mathrm{PV} \max }$, the reactive power capability can be increased from zero to nearly $46 \%$ in the maximum PV power generation condition. This will give the power factor range of unity to 0.91 leading/lagging. The $\mathrm{Q}$ capacity during no sun condition is then $110 \%$.

In all the studied cases, inverters with $10 \%$ increased ratings were used, to allow for ample reactive power capability.

\footnotetext{
* Some inverters are highly optimized for efficiency, and are not capable of Q injection, but this beyond the scope of this discussion.
} 


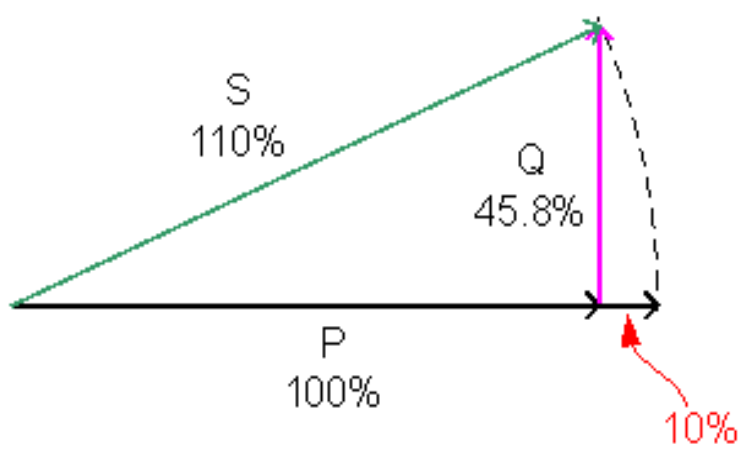

Figure 9. Relationship between inverter size and its reactive power capability

\subsubsection{Peak load, 5\%, $10 \%$, 30\% and 50\% Penetration, OLTC + SVR, Inverters Supplying Reactive Power}

The reactive power capabilities of PV inverters can be used to offset the reactive load. This reduces the reactive power flow on the distribution feeder, and in turn reduces the voltage drop along the feeder. Inverters are configured to supply reactive power, and their output capacity Q is equal to their ratings. As in baseline configuration 2, OLTC controls the primary side of SVR, and SVR controls the service voltage at the last customer. The feeder's voltage profile and the associated active and reactive power flows for penetration levels from 5\% to 50\% are shown from Figure 10 through Figure 17.

The performance is similar to the performance discussed for baseline configuration 2, so only the differences will be highlighted. Notice that the amount of required reactive compensation by the switched capacitor progressively reduces as the penetration level increases. At 30\% penetration, reactive power injected by the switched capacitor almost completely diminishes, and none is necessary for $50 \% \mathrm{PV}$ penetration. The amount of reactive power supplied by the substation is also progressively lower with increased levels of PV penetration; this results in lower current through the feeder and, consequently, in lower $\mathrm{I}^{2} \mathrm{R}$ and $\mathrm{I}^{2} \mathrm{X}$ power losses. Compared with baseline configuration 2 , losses are reduced as summarized in Table 6 . Note that since the inverter losses were neglected, these results are somewhat optimistic. A more detailed evaluation of losses will be a topic of future research.

Table 6. Reduction in feeder losses due to inverter $\mathbf{Q}$ support relative to baseline configuration 2

\begin{tabular}{|l|l|}
\hline PV penetration [\%] & $\begin{array}{l}\text { Loss reduction relative to } \\
\text { baseline configuration 2 [\%] }\end{array}$ \\
\hline 5 & 2 \\
\hline 10 & 2.5 \\
\hline 30 & 3.5 \\
\hline 50 & 7 \\
\hline
\end{tabular}




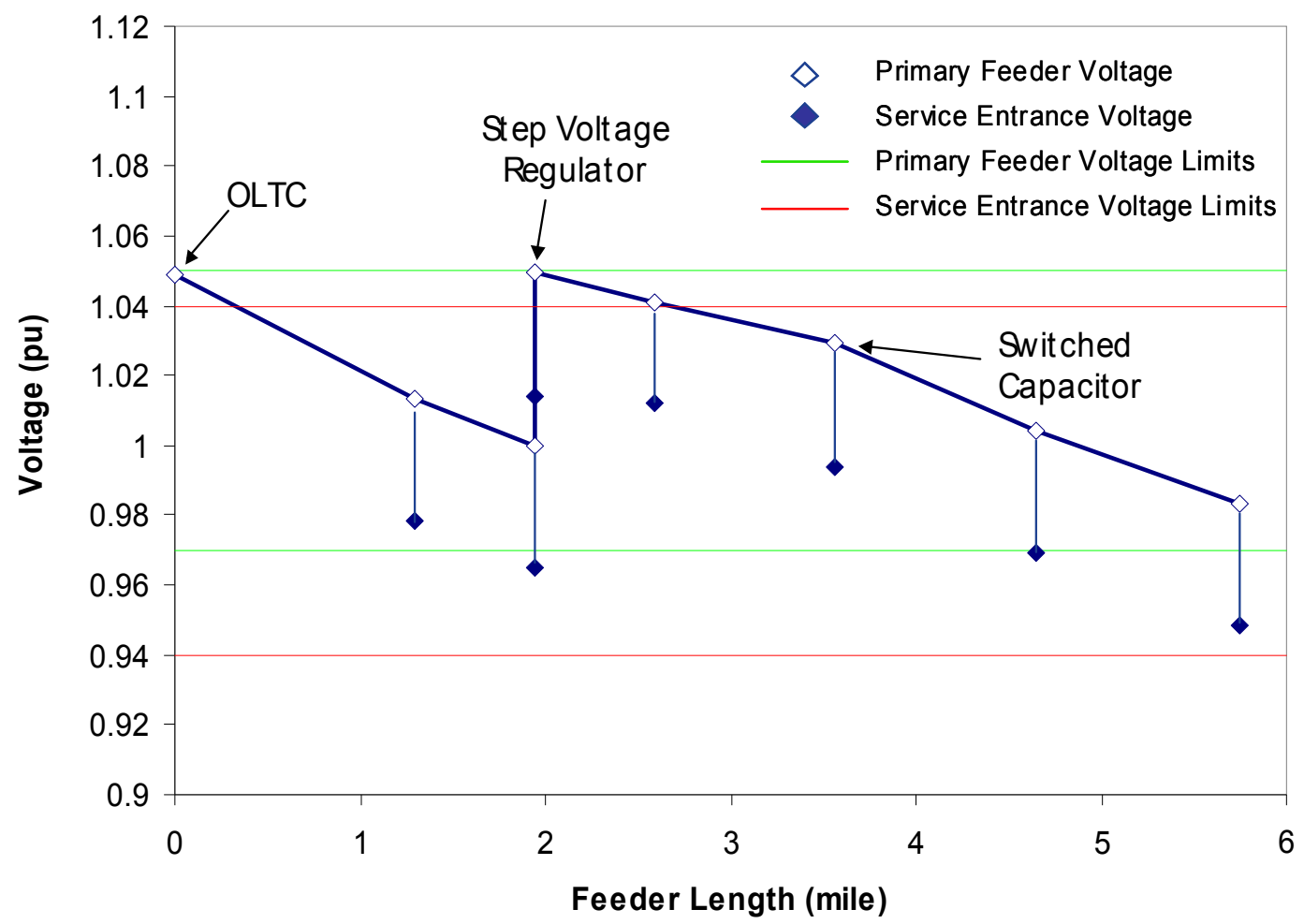

Figure 10. 5\% PV penetration voltage profile: peak load with SVR

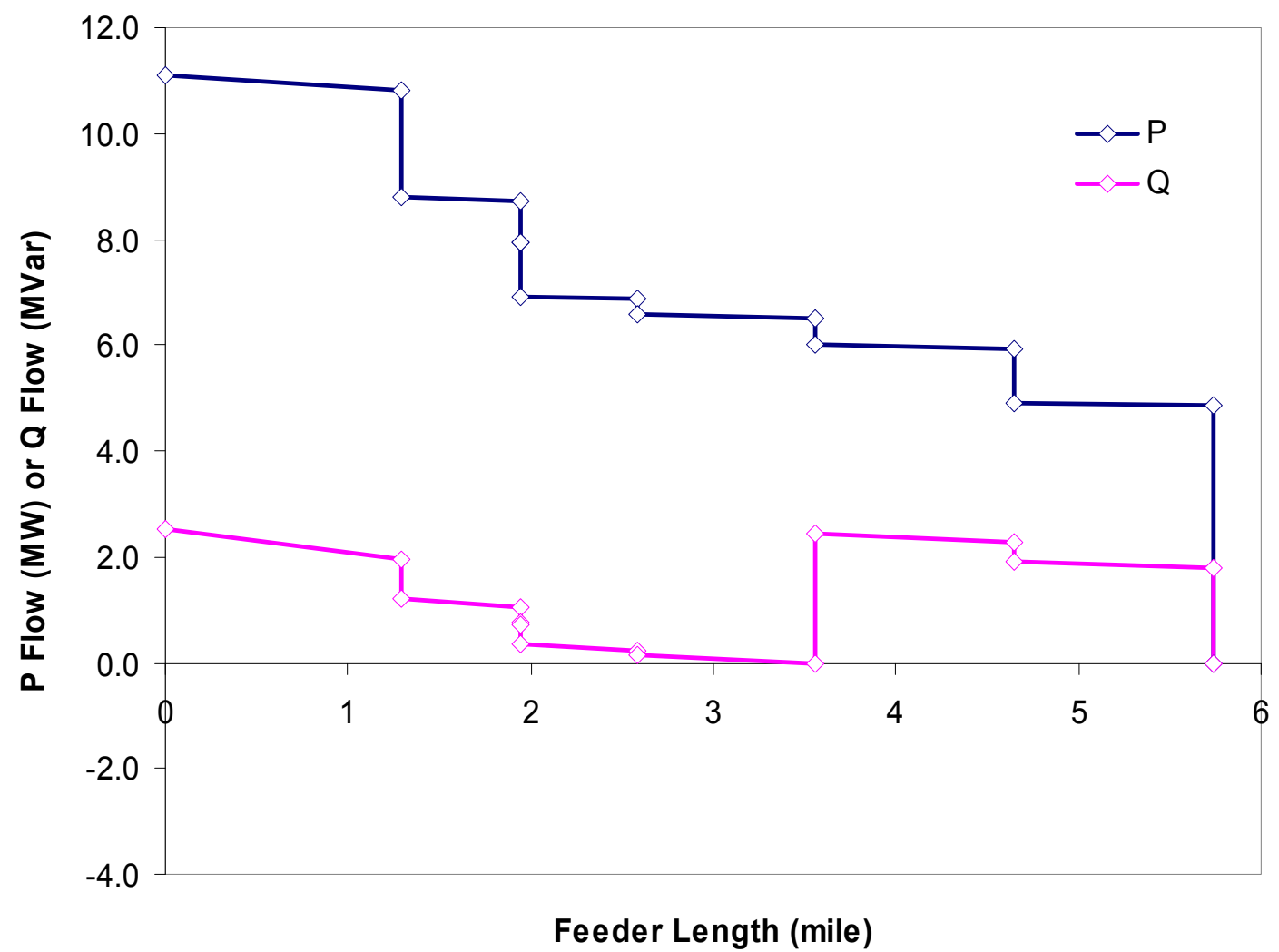

Figure 11. 5\% PV penetration power flow: peak load with SVR 


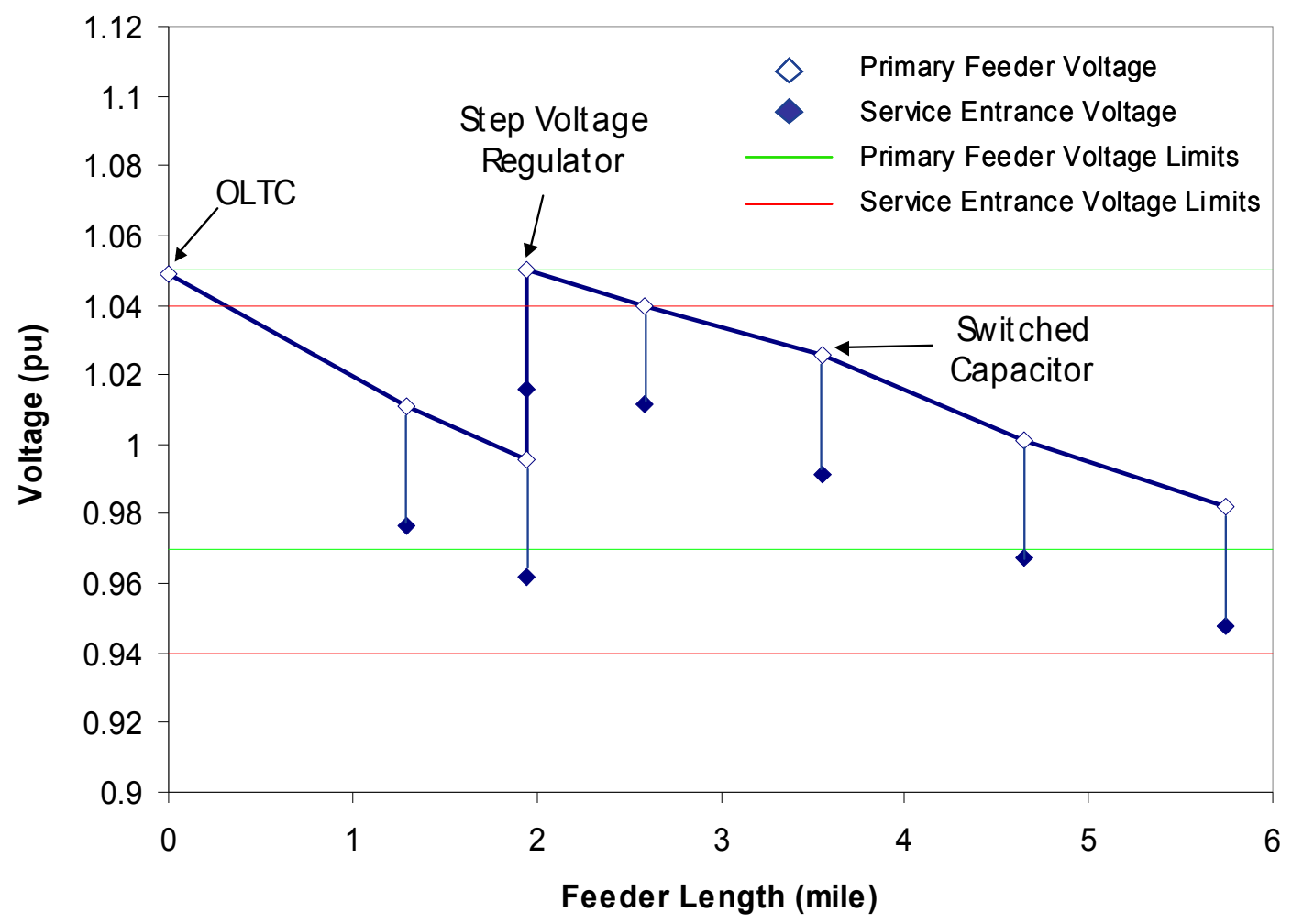

Figure 12. 10\% PV penetration voltage profile: peak load with SVR

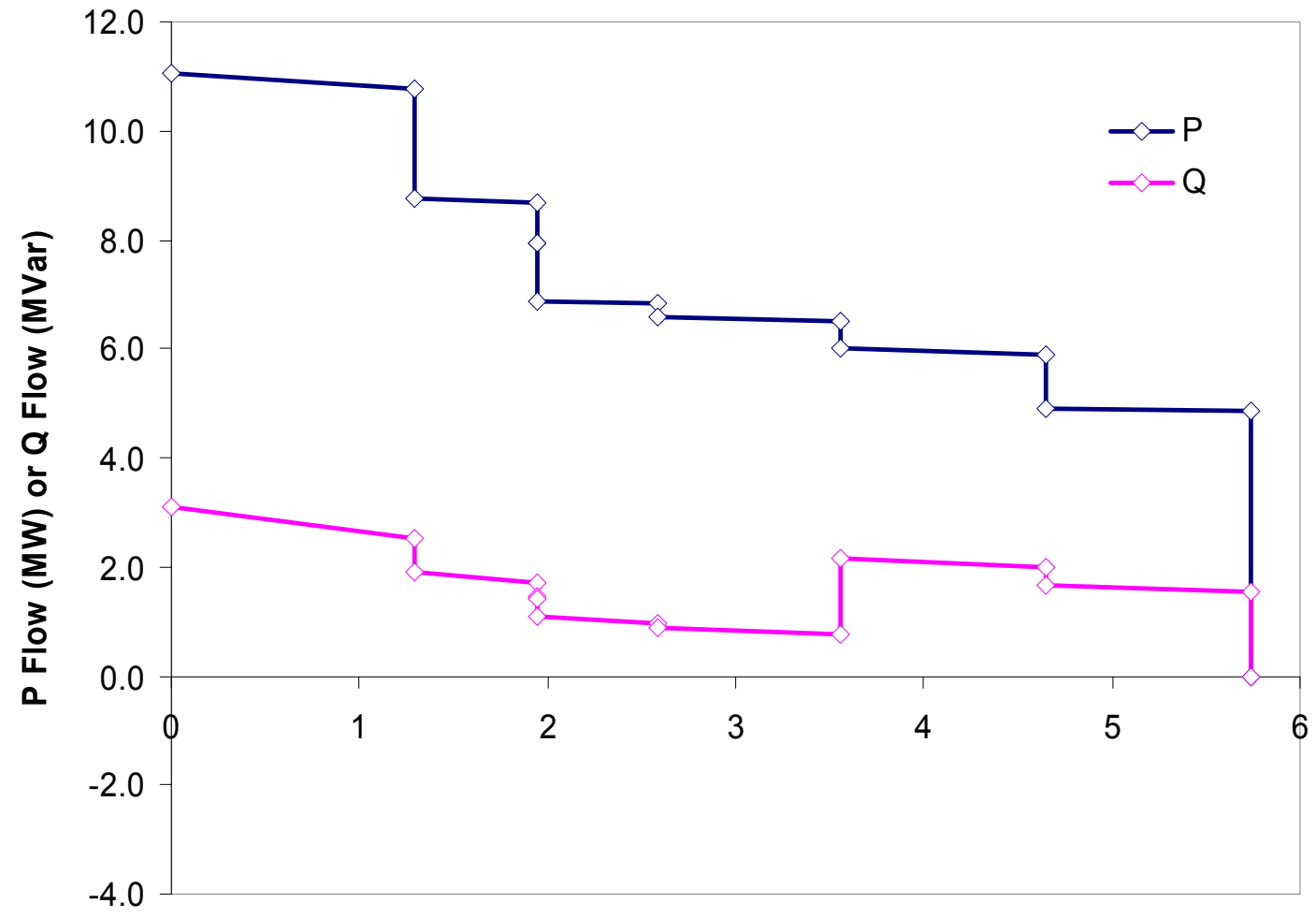

Feeder Length (mile)

Figure 13. 10\% PV penetration power flow: peak load with SVR 


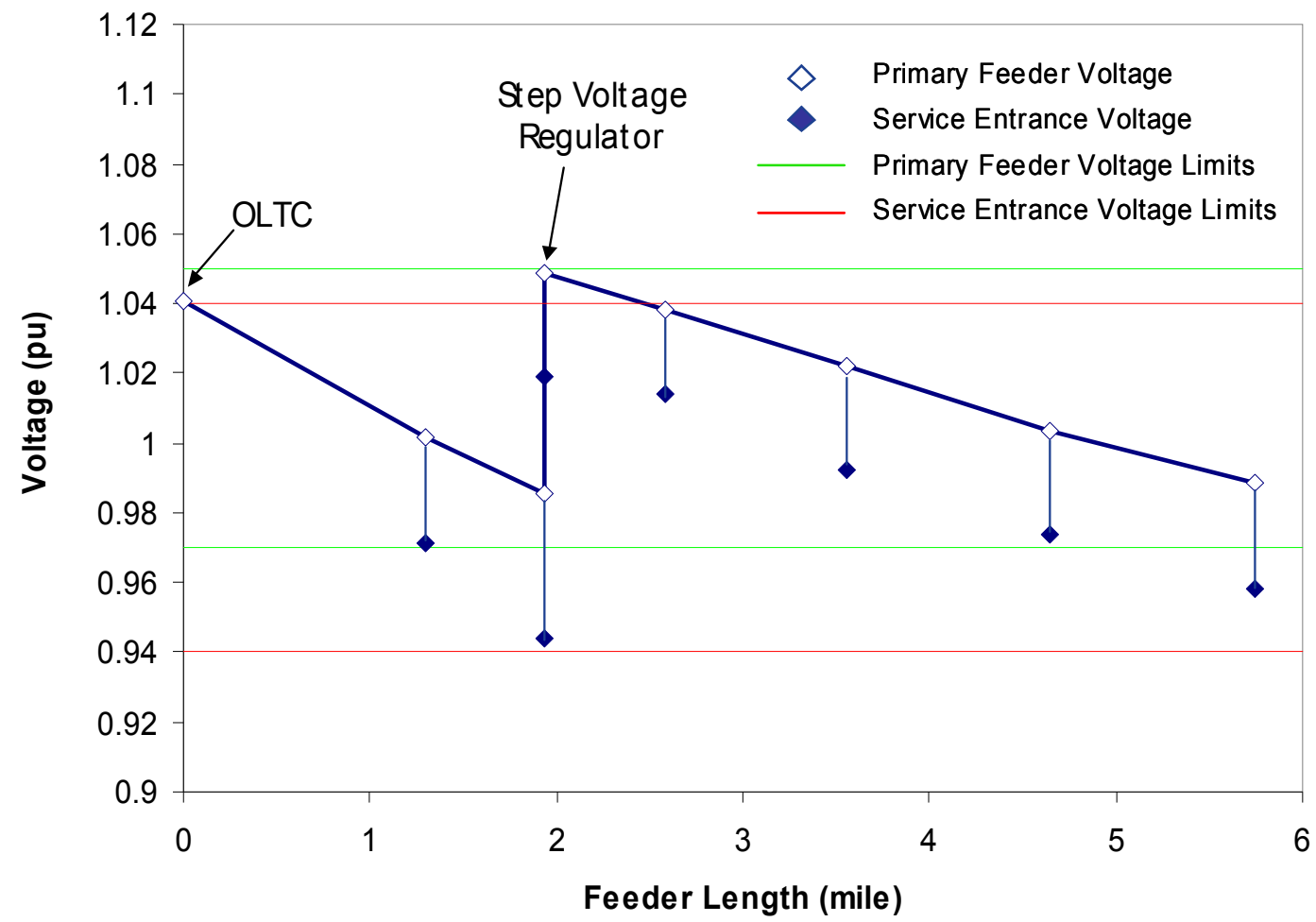

Figure 14. 30\% PV penetration voltage profile: peak load with SVR

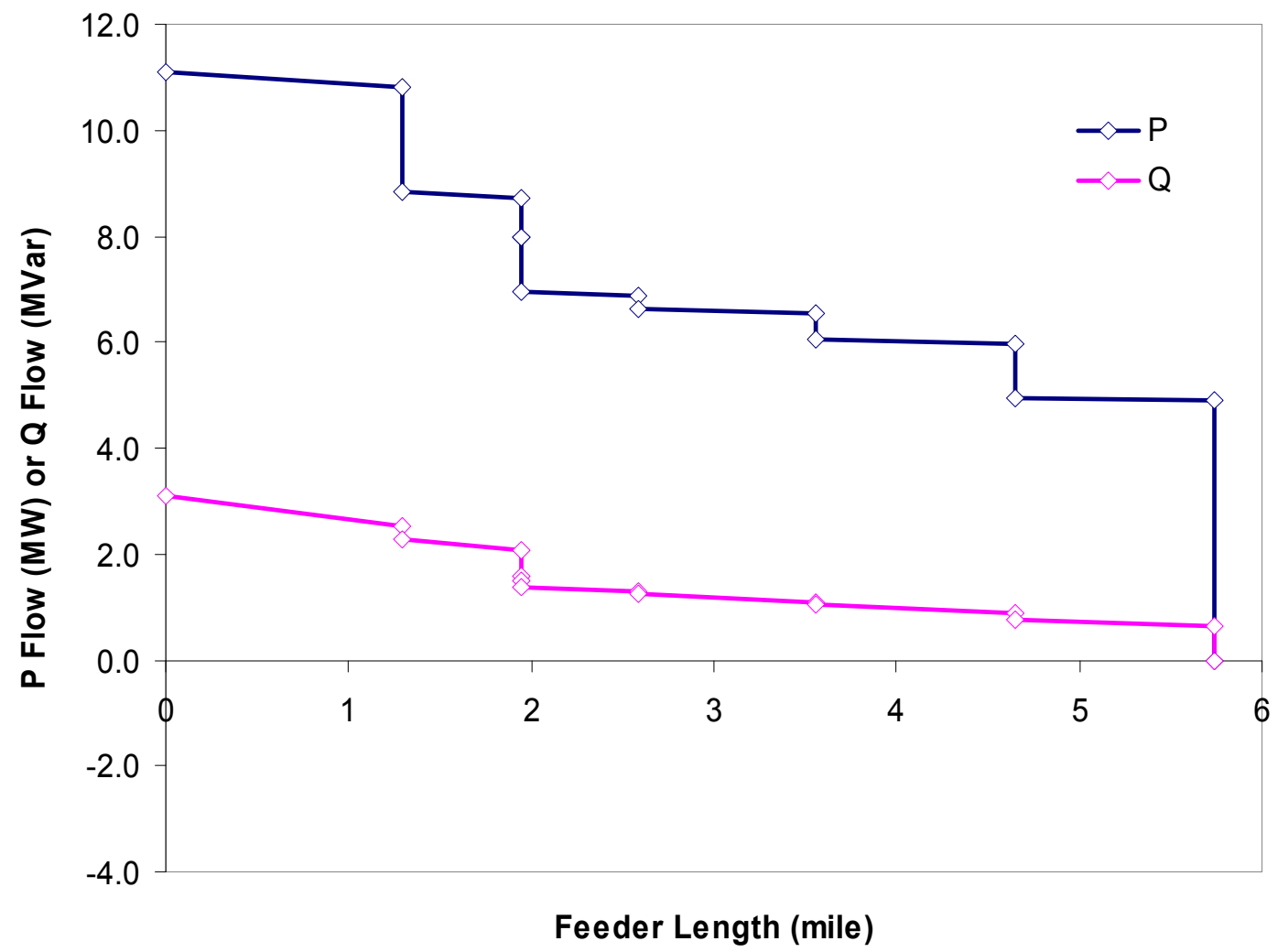

Figure 15. 30\% PV penetration power flow: peak load with SVR 


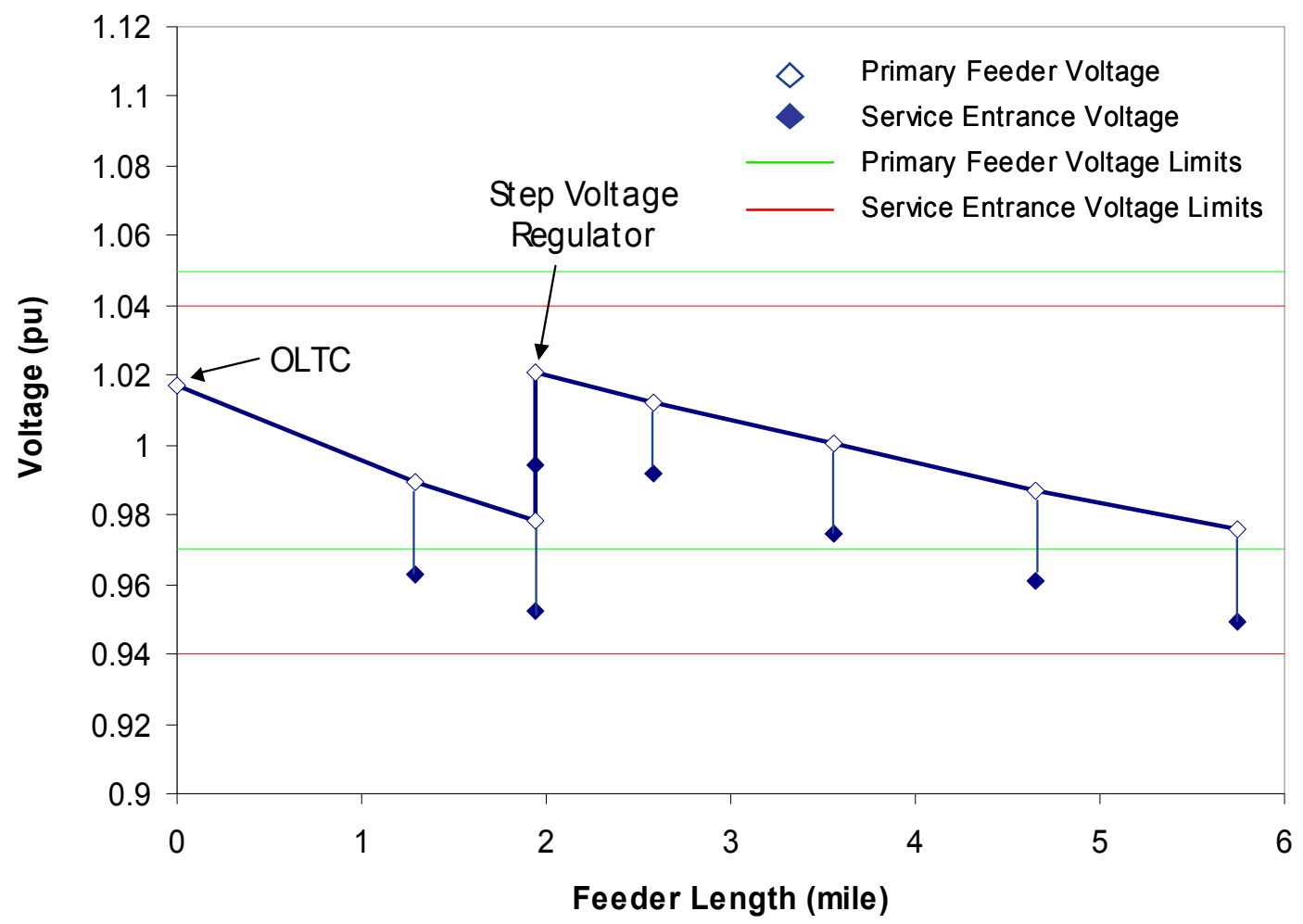

Figure 16. 50\% PV penetration voltage profile: peak load with SVR

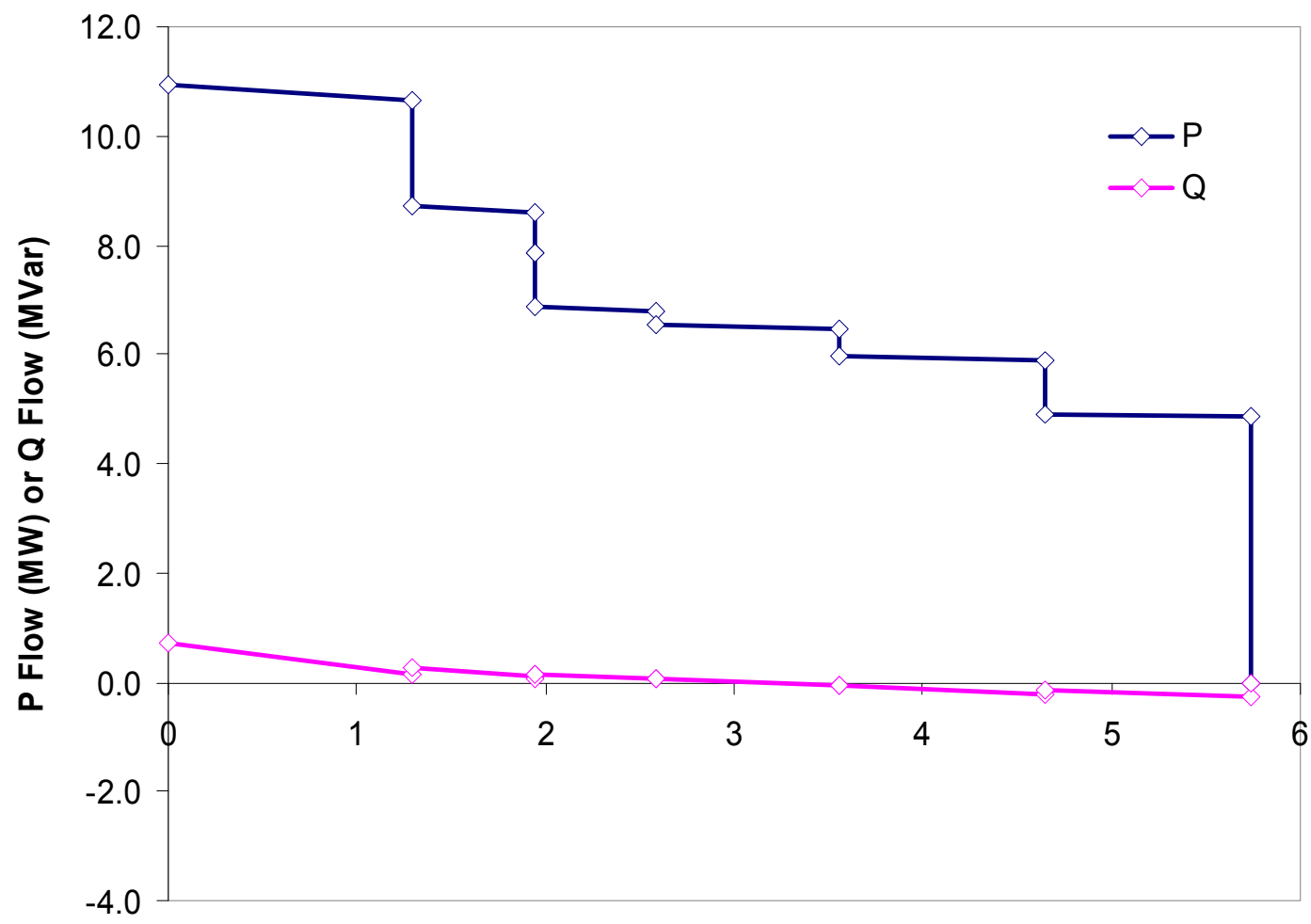

Feeder Length (mile)

Figure 17. 50\% PV penetration power flow: peak load with SVR 


\subsubsection{Peak Load, 50\% Penetration, OLTC, Inverters Supplying Reactive Power}

Similar performance is observed when the inverters are used to supply reactive power in the circuit of baseline configuration 1 . For brevity, only the $50 \%$ penetration case is presented. Here too, the reactive power flow through the feeder is reduced significantly, minimizing power losses on the feeder. In this case, the primary circuit voltage is slightly below the limit at the last load - this is not important since the service voltage is still maintained within the desired range, and the primary circuit limits are only a guideline.

The voltage profile on the feeder is show in Figure 18 and the corresponding P and Q flows are shown in Figure 19.

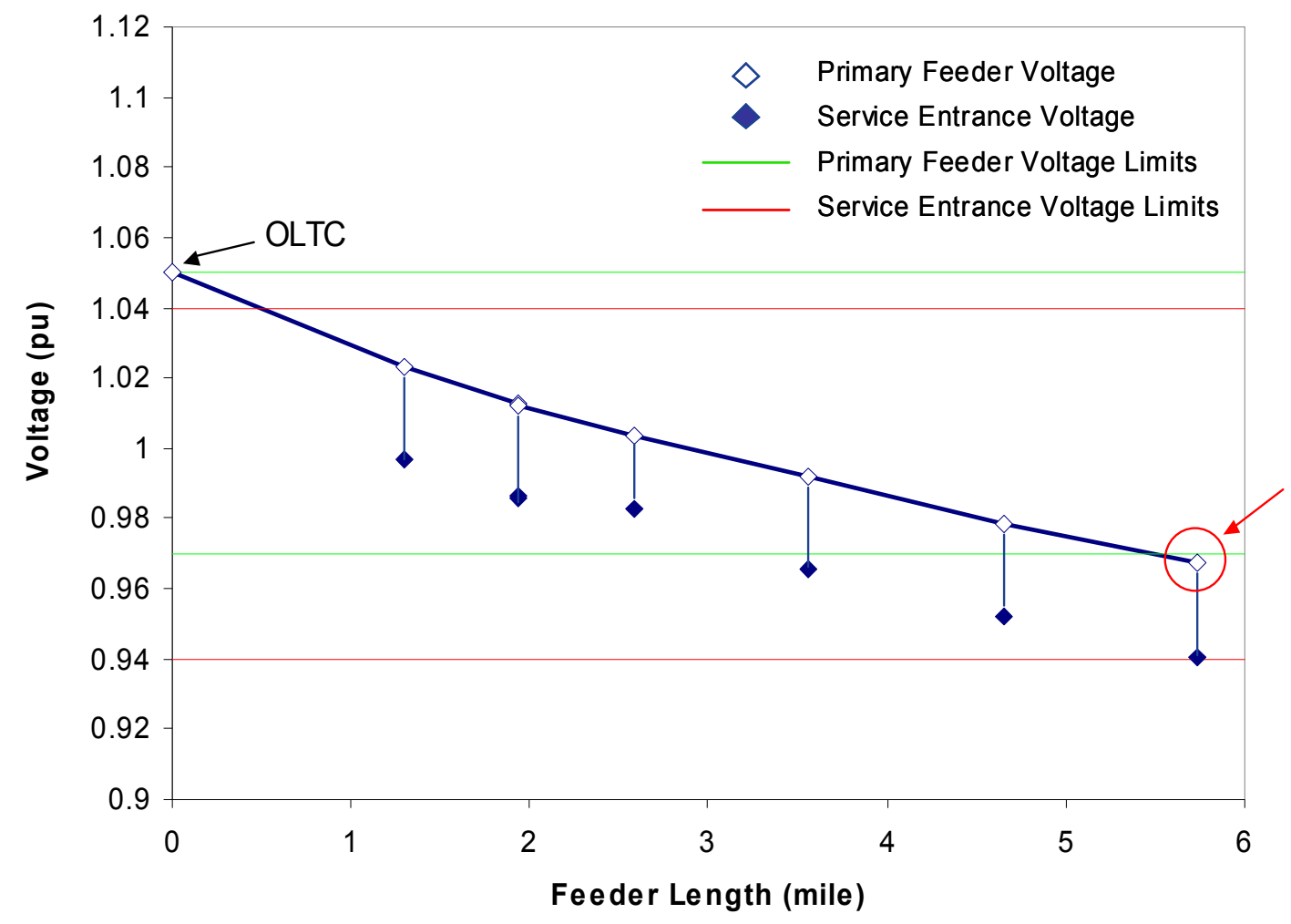

Figure 18. 50\% PV penetration voltage profile: peak load with inverter only 


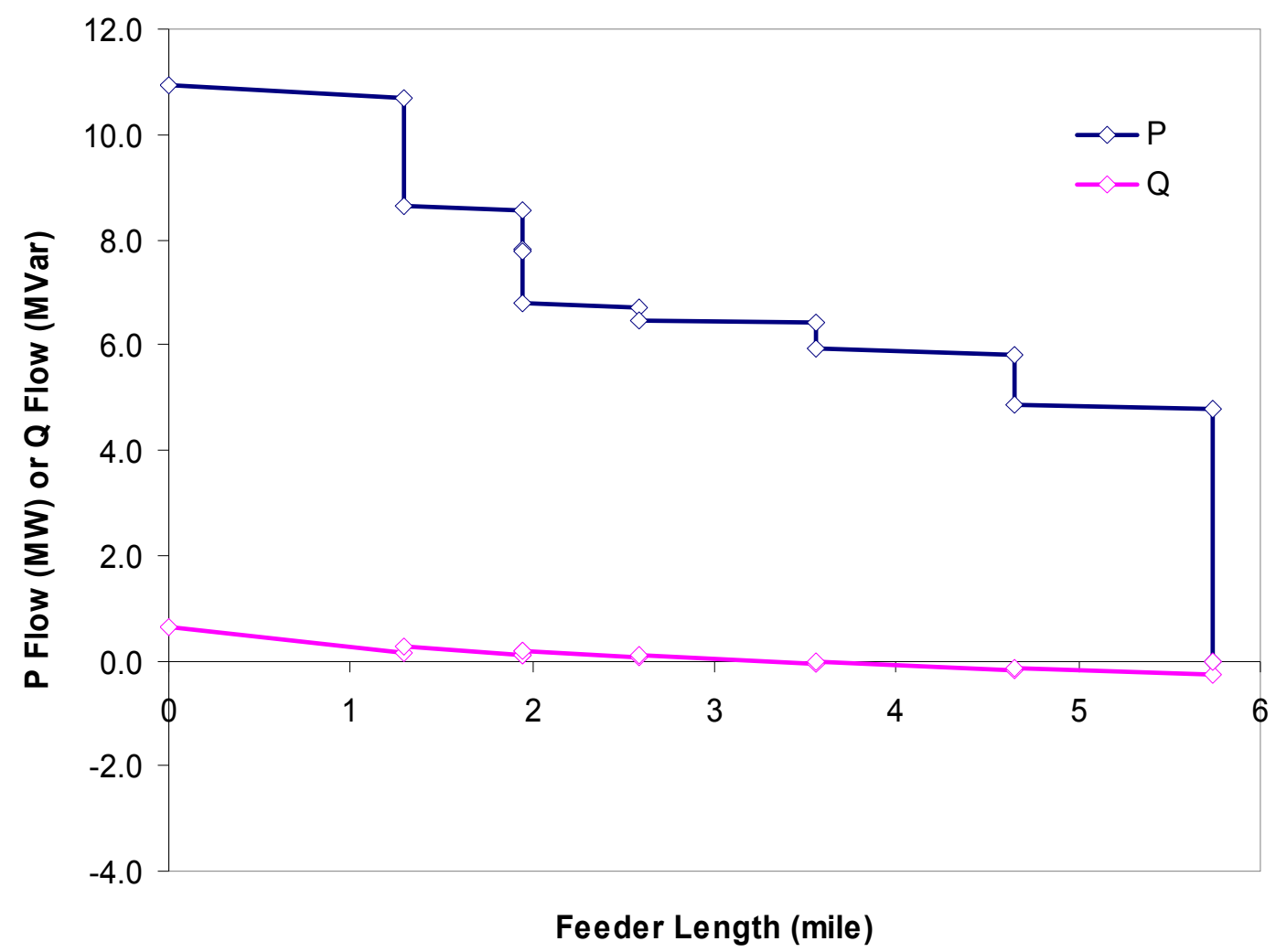

Figure 19. 50\% PV penetration power flow: peak load with inverters only

\subsubsection{Power Export, 50\% Penetration, OLTC, IEEE 1547 Inverters}

This is the second part of the case study, and deals with power export through the feeder. Work begins with an inverter that is compliant with IEEE 1547, and combined with an OLTC that is controlling the voltage at the service connection of the last load. The voltage profile is shown in Figure 20, and the corresponding active and reactive power flows are shown in Figure 21.

Relative to baseline configuration 1, a switched capacitor is not used, and the OLTC lowers the voltage at the substation to allow for the rise due to reverse power flow. As expected, voltage rises with increased distance from the substation, since the power flow is now towards the substation not away from it. This negative power flow is also indicated in Figure 21. Starting from the feeder's end, power flow is progressively more negative as generation is collected by distributed PV sources. Notice that the slope of the power curve between the nodes continues to be negative, because losses are still in the "same direction," as in the baseline cases.

The resulting Q flow is relatively low; Q supplied from the substation end covers only feeder $\mathrm{Q}$ losses, since the inverters operate at unity power factor.

This is a simple and effective measure, and the performance of the feeder is acceptable. 


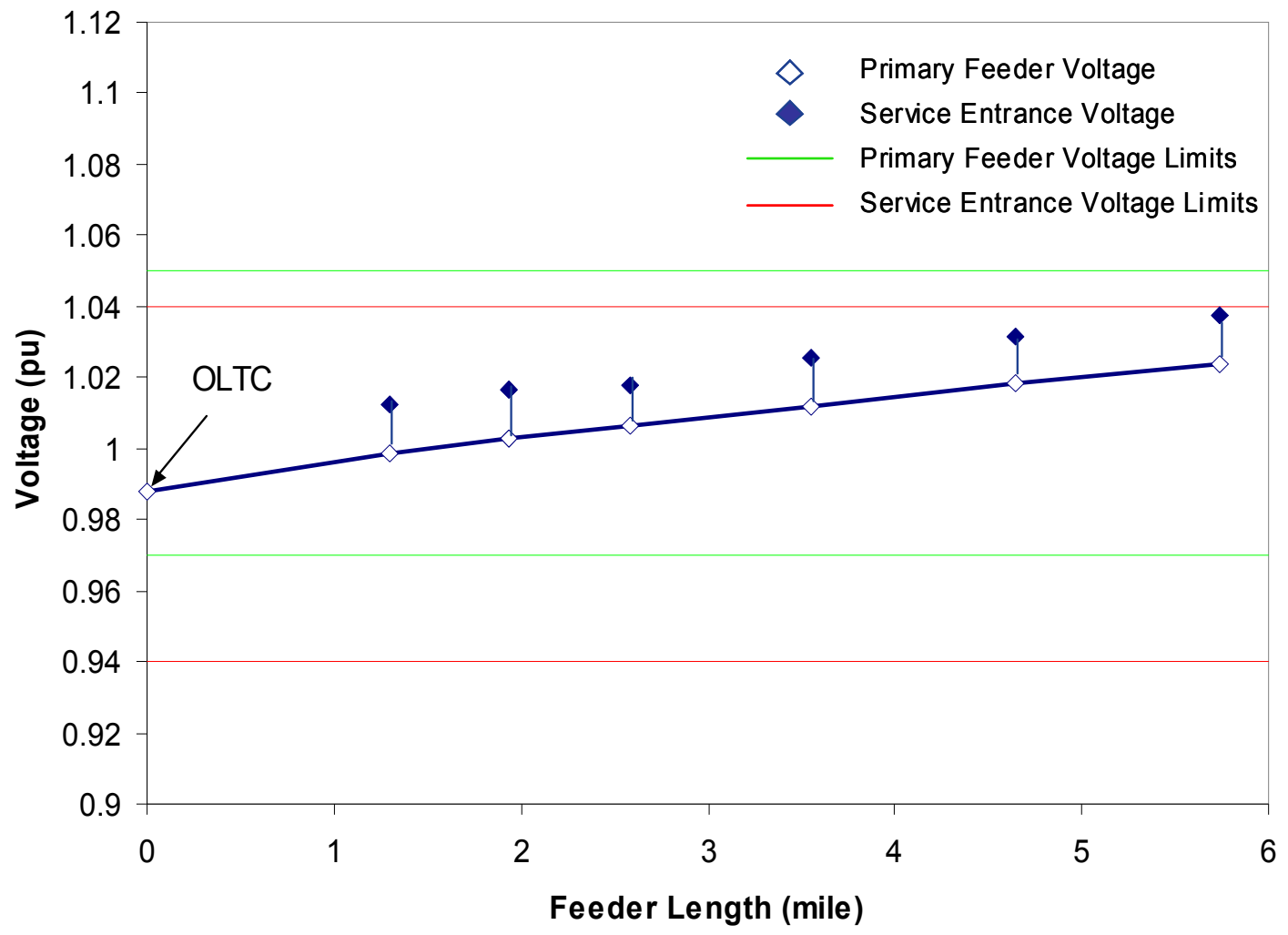

Figure 20.50\% PV penetration: voltage profile at max reverse power flow with OLTC

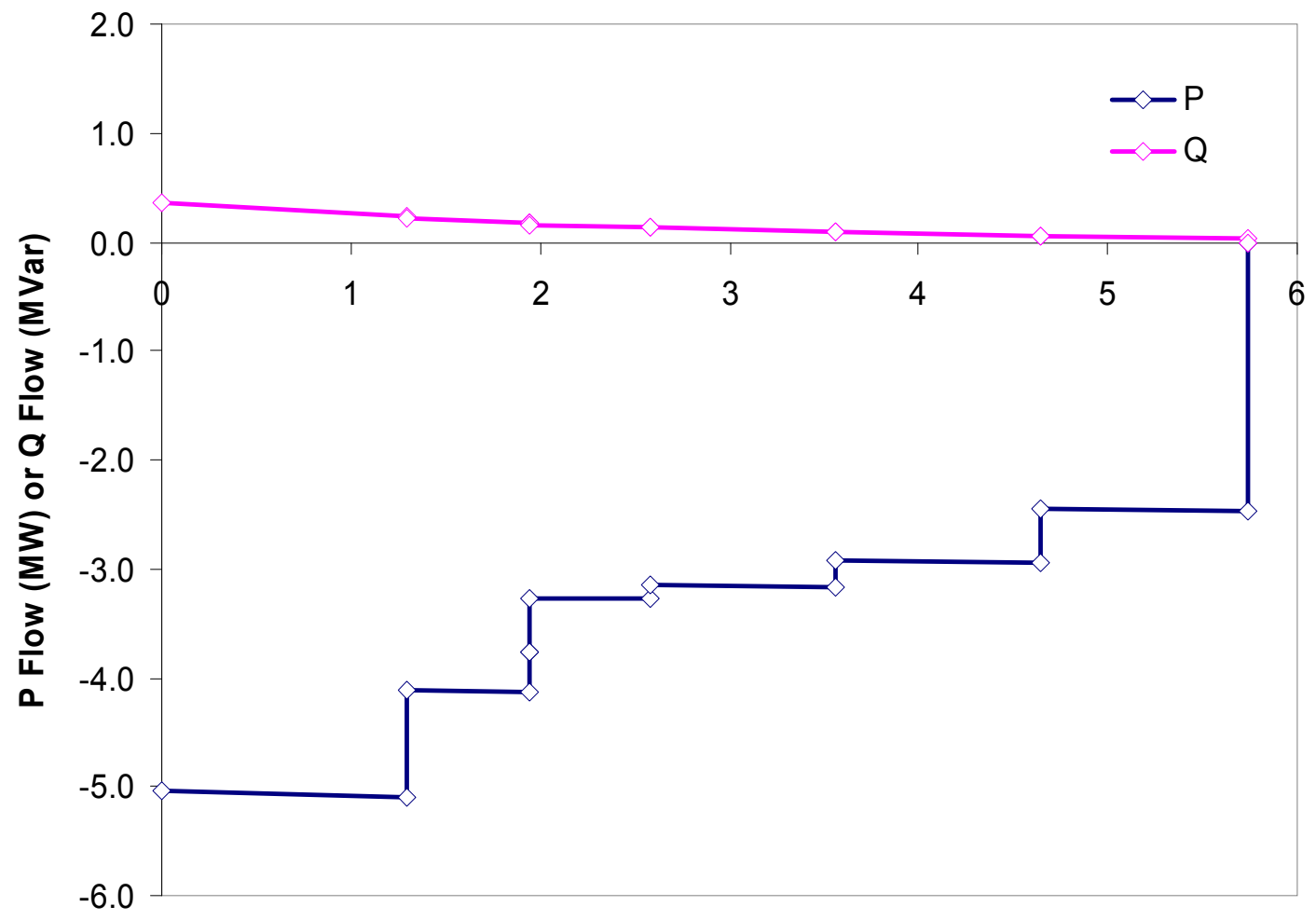

Feeder Length (mile)

Figure 21. 50\% PV penetration: power flow at max reverse power flow with OLTC 


\subsubsection{Power Export, 50\% Penetration, OLTC, Inverters Controlling Feeder Voltage}

In the following cases, the role of inverters with capabilities beyond the IEEE 1547 requirements is reviewed and compared with cases studied in previous sections.

If the requirement for the unity power factor operation of inverters were removed, the instinctive reaction would be to allow inverters to control the voltage at their terminals. This case is representative of such a strategy. The voltage profile is shown in Figure 22 and the active and reactive power flow is shown in Figure 23. The resulting voltage profile is nearly flat, as was desired, and active power flow is as it was in the previous case. Reactive power flow is, however, interesting relative to the previous case. The inverters are trying to reduce the voltage, and they accomplish this by absorbing reactive power, i.e., by operating as inductors. The resulting inductive loading of the feeder is substantial, as indicated by the approximately 1.5 MVAr supplied from the substation.

This is detrimental in two ways: first, feeder losses are increased due to unnecessary reactive power flow, and second, the reactive power demand on the transmission system is increased because of the use of distributed PV. Most traditional generators are based on synchronous machines, and they normally supply reactive power to the system, and do not absorb it. It would be beneficial to change the control strategy for the inverter and combine it with feeder voltage control to allow for net export of reactive power. This is discussed in the next section.

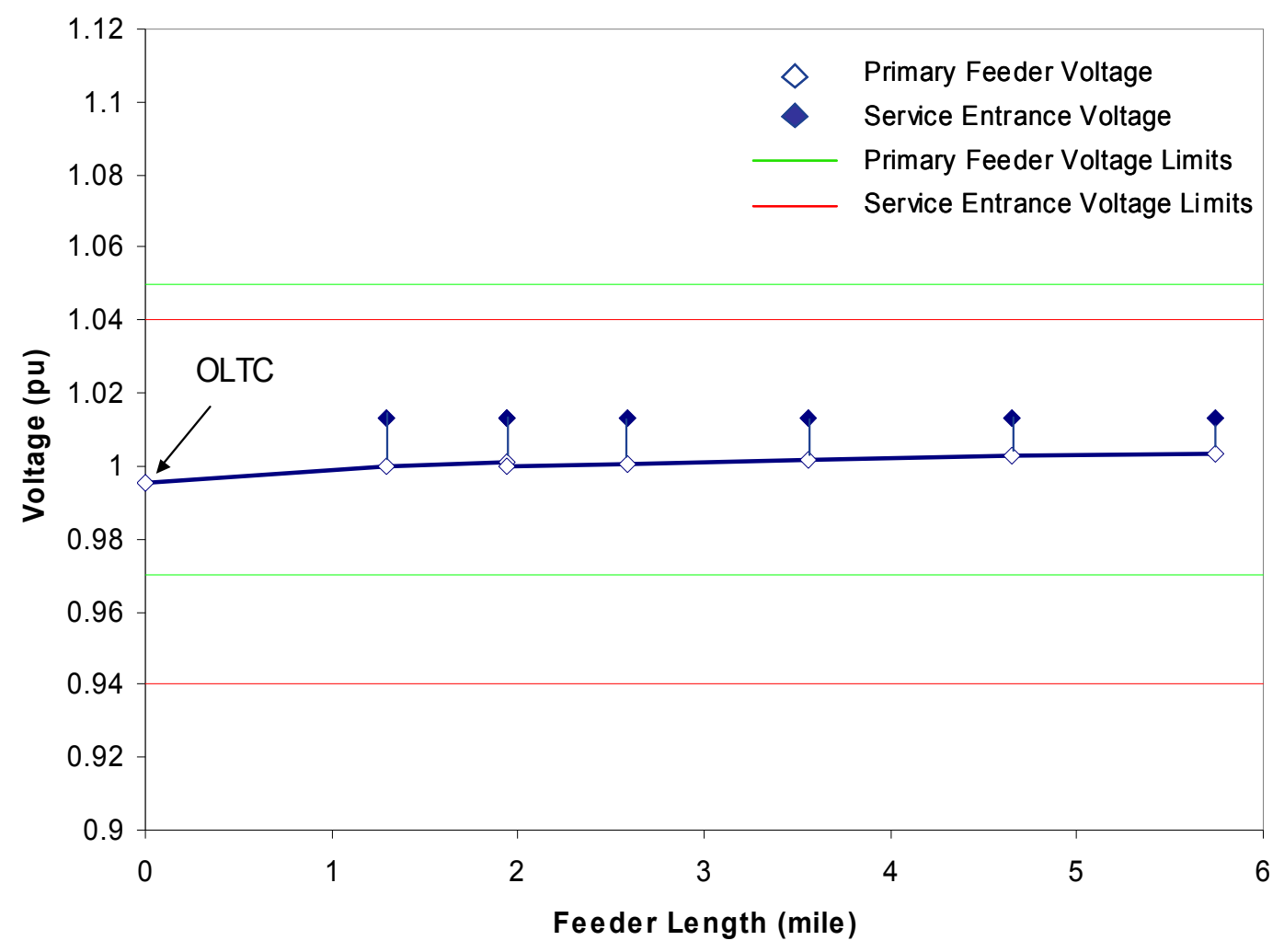

Figure 22. 50\% PV penetration voltage profile: inverter voltage support 


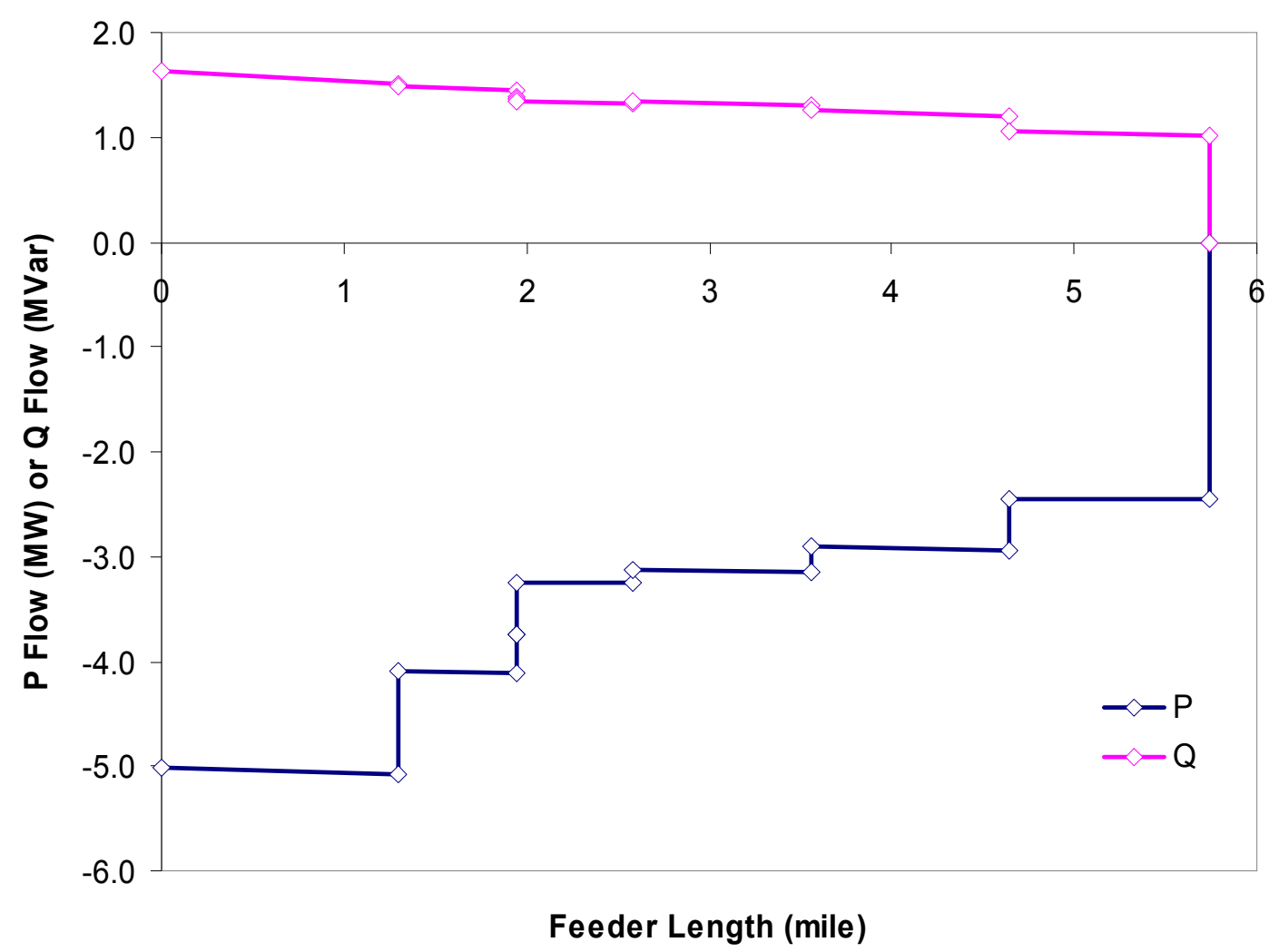

Figure 23. 50\% PV penetration power flow: inverter voltage support

\subsubsection{Power Export, 50\% Penetration, OLTC, Inverters Supplying Capacitive Reactive Power}

In this case, the control of the inverters is combined with the control of the OLTC in order to allow for Q export from the feeder.

Distributed PV generation is envisioned to displace some of the conventional generators in the near future. An important feature of conventional generators is their ability to provide reactive power to the system. Conventional generators can generate or absorb reactive power within the limits of the exciter, and they are normally configured to supply reactive power. The PV inverters have a similar reactive power capability. PV inverters generally have analogous capabilities, but since they are connected to the distribution system their operation has to be coordinated with the feeder voltage control in order to allow net reactive power export.

This case illustrates a control strategy that allows net export; the OLTC now reduces the output of the substation to the lower limit and the inverters raise the service voltage to the upper limit. The resulting voltage profile is shown in Figure 24, and the active and reactive power flows are shown in Figure 25.

As shown in Figure 25, net Q export is accomplished, but it is hampered by the voltage constraints on the feeder. Specifically, the Q capability of the equivalent inverter at the last node is above $1 \mathrm{MVAr}$ and it supplies less than 0.5 MVAr. This is a consequence of voltage 
limitations and feeder topology, and given the availability of the voltage control equipment, nothing can be done to increase Q supply from the last node. An important conclusion is that over-sizing the inverters to provide Q support does not always help, as it can be restrained by the inverter placement on the feeder and available voltage control equipment.

In the next case, a way to remedy this limitation is illustrated. SVR is used to increase Q flow through the feeder.

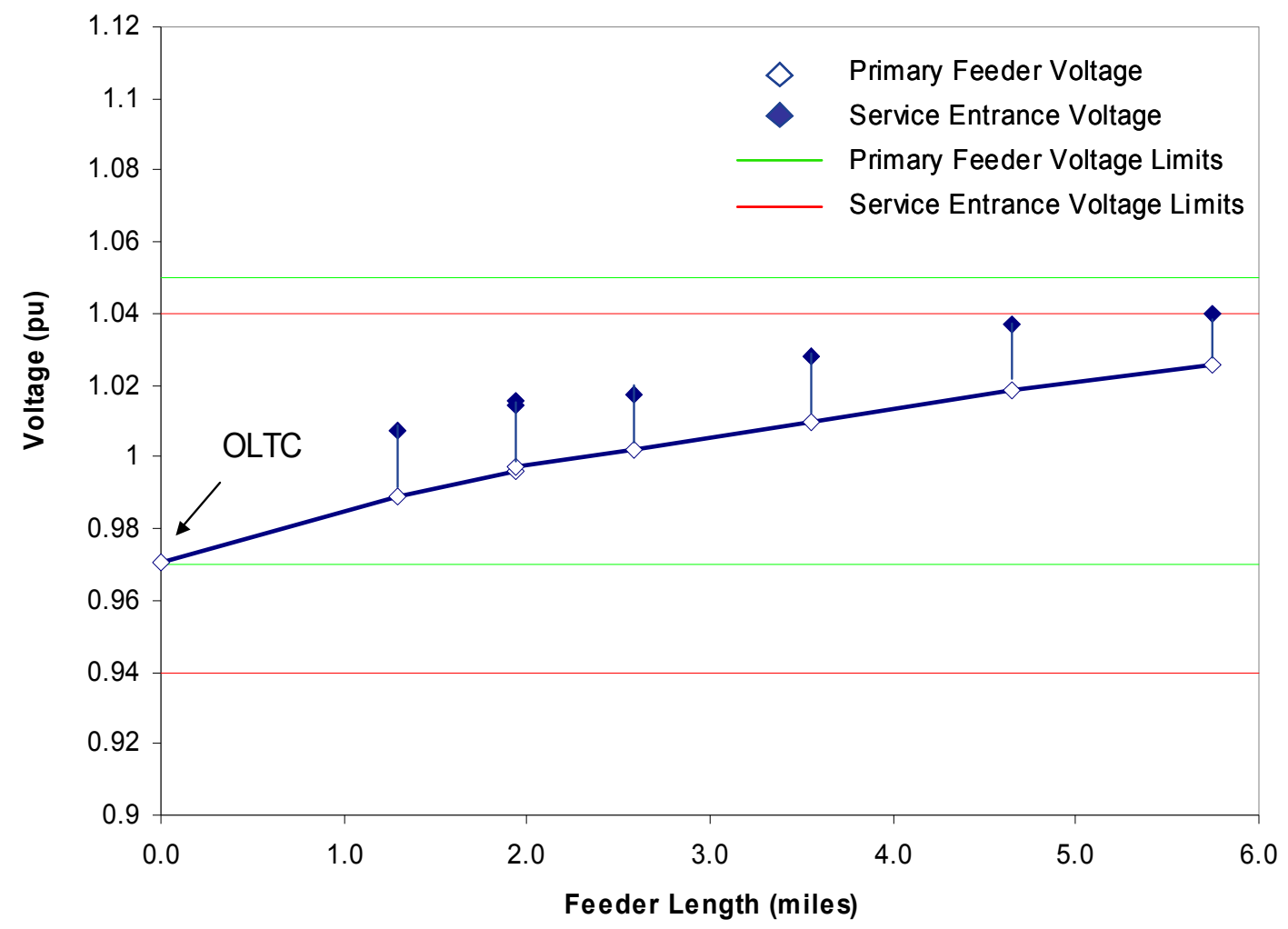

Figure 24. 50\% PV penetration voltage profile: inverter VAR support 


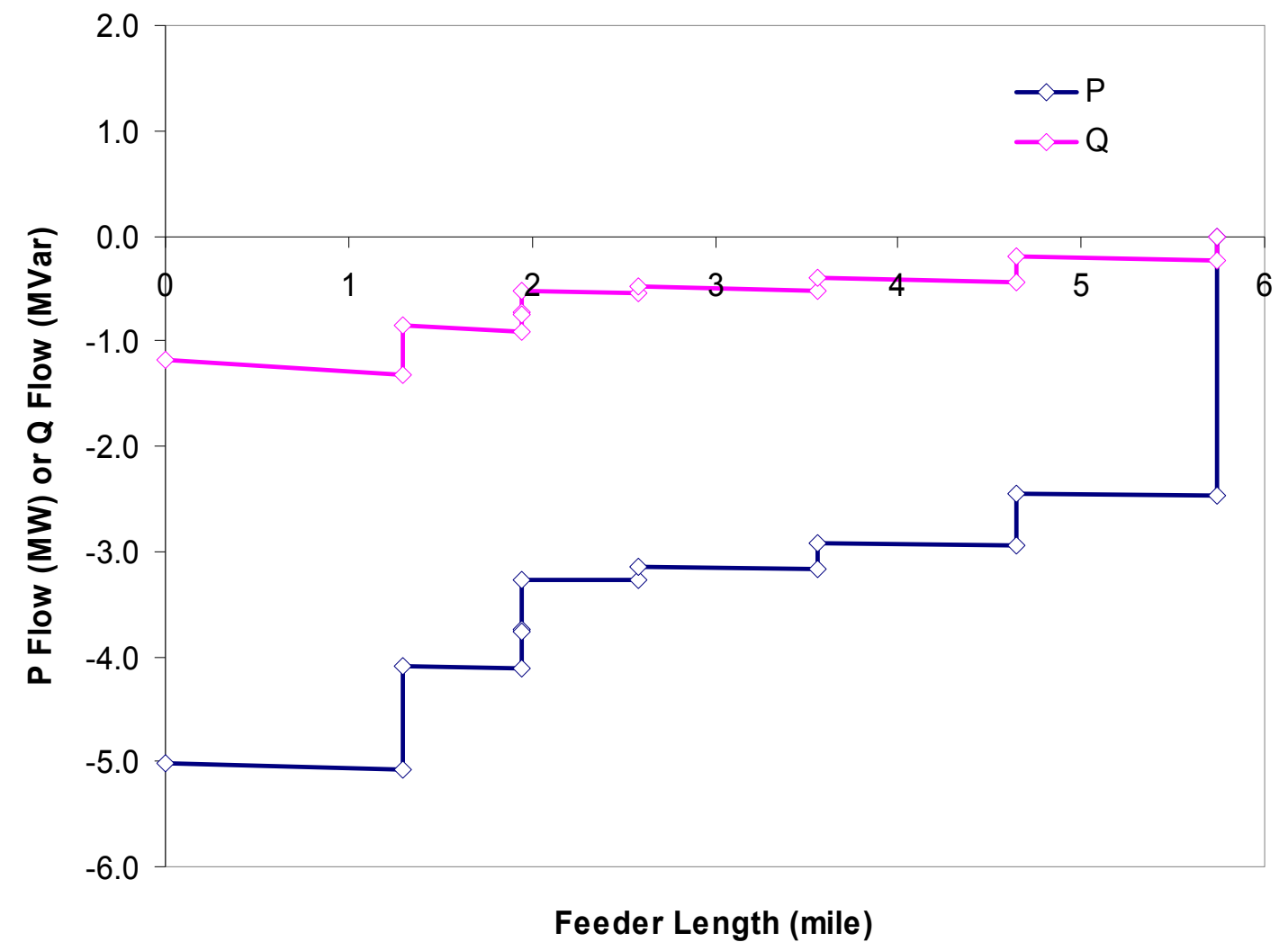

Figure 25. 50\% PV penetration power flow: inverter VAR support

\subsubsection{Power Export, 50\% Penetration, OLTC + SVR, Inverters Supplying Capacitive Reactive Power}

In this case, the coordinated action of the OLTC, the SVR, and the inverters is used to maximize Q export from the feeder and use up all the available $\mathrm{Q}$ capacity from the inverters. The resulting voltage profile is shown in Figure 26, and the corresponding $\mathrm{P}$ and Q flows are shown in Figure 27.

The Q export to the feeder is now maximized. It is slightly over 2 MVAr at the substation, and the feeder and service voltages still remain within the desired limits. Conceptually, this is a simple modification of the circuit, and it can be generalized to maximize export of $Q$ on any feeder regardless of length. Using such a control strategy enables the full utilization of the inverters' Q capabilities, and enables distributed PV to displace conventional generation without compromising performance. 


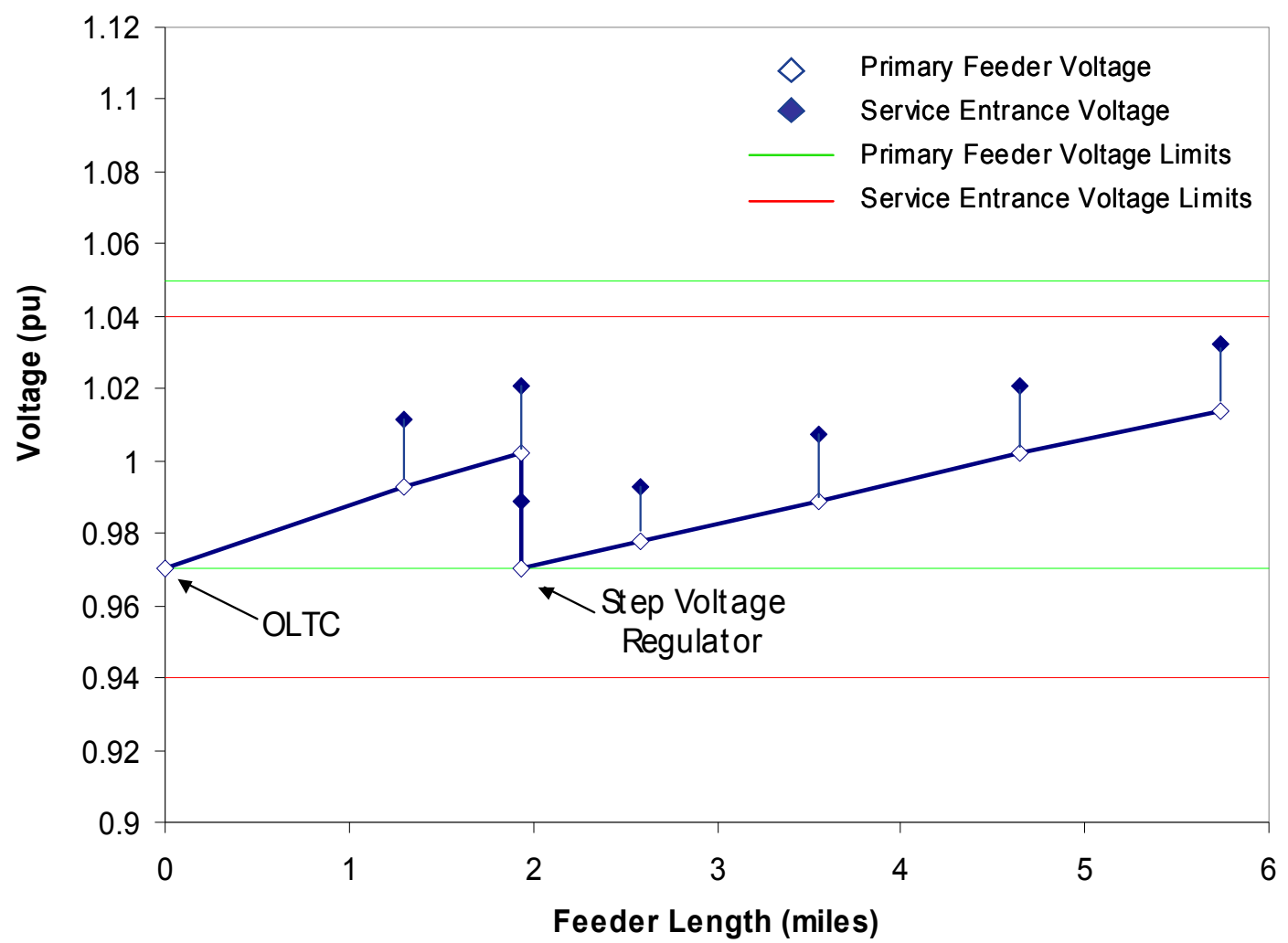

Figure 26. 50\% PV penetration voltage profile: inverter VAR support with SVR

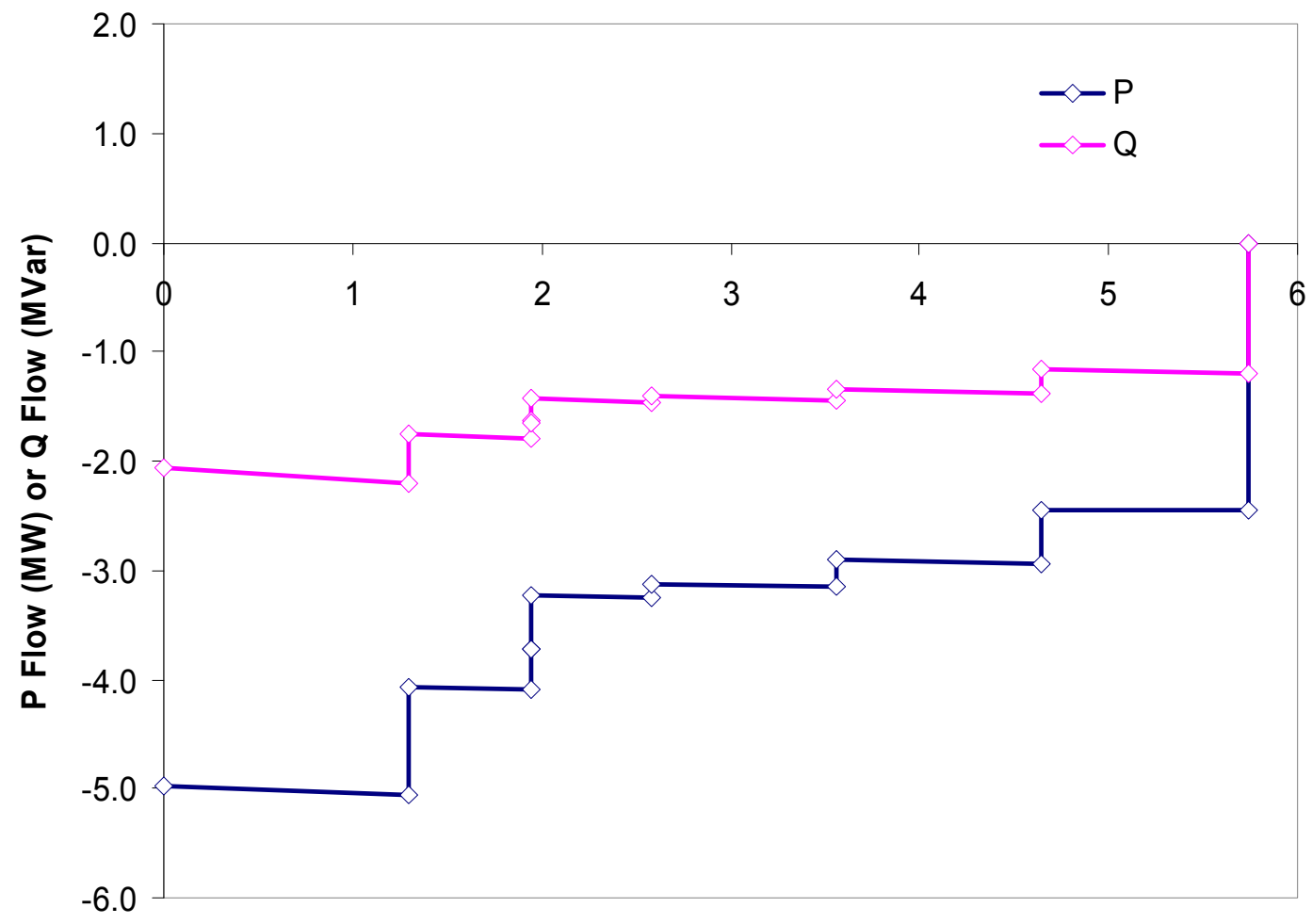

Feeder Length (mile)

Figure 27. 50\% PV penetration power flow: inverter VAR support with SVR 


\subsubsection{Power Export, 50\% Penetration, OLTC, Inverters Controlling Total Service Power Factor}

Finally, the inverters are used to control the power factor at their total service connection, making the connection slightly capacitive in order to cover for the reactive drop through the service transformer and the corresponding feeder impedance.

Figure 28 and Figure 29 show the resulting voltage profile and the P Q flow of the study feeder. This case demonstrates that the inverters can achieve approximately unity PF at the feeder connection to the substation - a slightly better performance relative to the IEEE 1547 case, where reactive power flow was supplied from the substation.

Another very important characteristic of this control strategy, relative to most of the others presented, is that it can be implemented using local measurements only. To illustrate some of the control schemes, voltage magnitude was used at the service entrance of the last load to control the OLTC. Such setup requires a point-to-point communication link, or if a more general setup is desired, a communication link should exist between the OLTC and all of the service voltage connections to allow for control based on the worst-case voltage. Much work is needed to come up with an optimal communication infrastructure to ensure effectiveness without excessive costs.

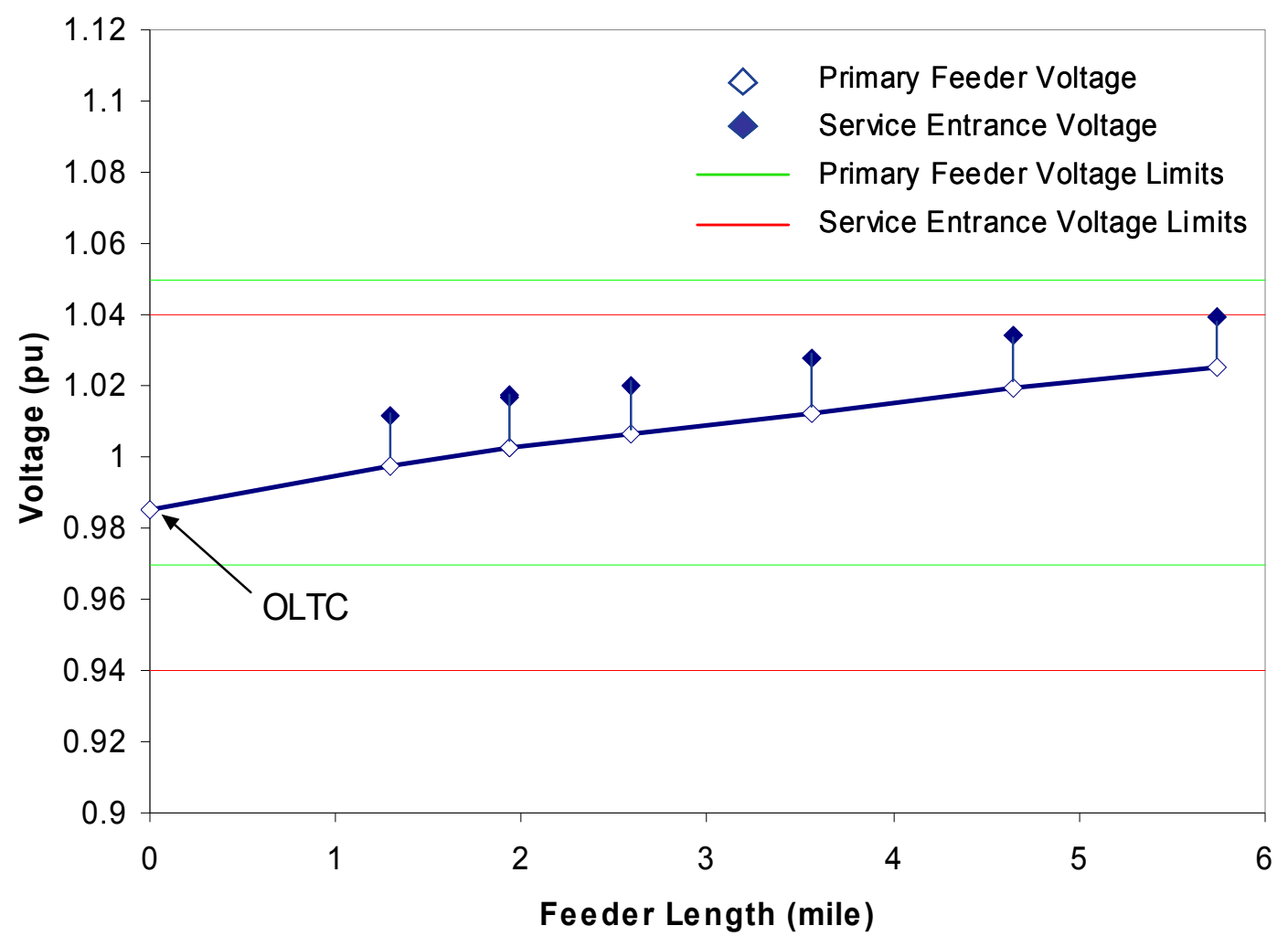

Figure 28. 50\% PV penetration voltage profile: inverter power factor correction 


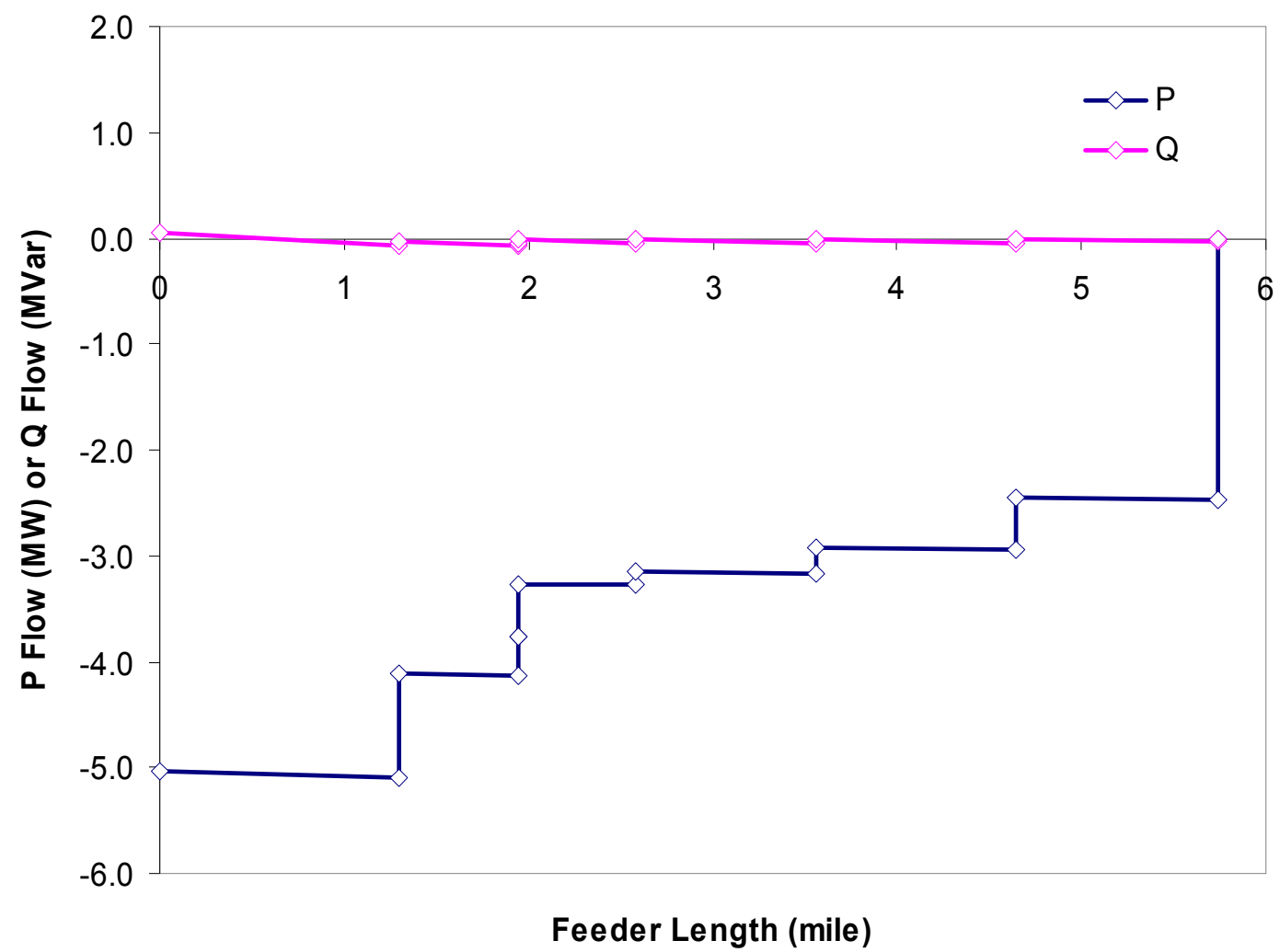

Figure 29. 50\% PV penetration power flow: inverter power factor correction 


\subsection{Conclusions and Recommendations}

In this study, a representative distribution feeder was selected for analyzing the impact of different penetrations of PV on the feeder voltage regulation. Commonly used voltage regulation equipment, such as a step voltage regulator and a switched capacitor, were applied individually and in combinations to create different feeder configurations. Two extreme scenarios, peak load and maximum reverse power flow, were simulated in order to study the feeder's voltage performance under different conditions.

A series of case studies was conducted with different penetrations of PV, each assuming several commonly used voltage regulation methods. The study results show:

- Reverse power flow at all studied PV penetration levels can be accommodated using traditional utility equipment with perhaps modified controls.

- Voltage rise on the secondary circuits is significant and it should be included in the analysis. Establishing a communication link between service points (customer meter connections) and the utility equipment is helpful as it enables explicit control over the worst-case voltage.

In all the cases studied, PV inverters can positively contribute to the feeder voltage regulation and result in an improved voltage profile. At a high enough penetration, PV inverters may be able to provide feeder voltage support. The study results show:

- At a low PV penetration level (5\%), inverters do not make a significant impact on the feeder's voltage regulation during peak load.

- At medium a PV penetration level (10\%), inverter voltage support can help reduce the size of the conventional voltage support capacitors by nearly $40 \%$.

- At high PV penetration levels (30\%-50\%), PV inverters might be sufficient to provide all of the feeder voltage support.

As the inverter-coupled PV sources displace conventional generation, they will also have to match most of their performance characteristics. With respect to reactive power supply to the system, PV inverters are disadvantaged because their reactive power injection may be limited by the feeder voltage limits. This can be resolved by coordinated control of utility equipment and inverters, and in some cases additional utility equipment might be needed to take full advantage of the inverters' reactive power capabilities.

Recommendations for future research in this field are:

- Develop a set of recommended practices for reconciling existing feeder voltage control techniques with high penetration of distributed PV. This work illustrates several such cases, but it is limited to one feeder topology. A more comprehensive coverage of feeder topologies would be beneficial.

- Develop a set of recommended practices for modeling PV inverters for load flow analysis and for other relevant planning purposes, such as short circuit current 
calculations. At the same time, expand the number of possible control options for traditional equipment in the analysis software. This would result in a more consistent understanding of the issues across the industry and would simplify the test case setup to evaluate any specific situation.

- Create a set of benchmark cases to facilitate testing the models and the associated software. Some of the confusion and unwarranted concerns about the impact of PV generation may be a result of inconsistent and incorrect modeling.

- Develop automated screening tools that will enable evaluation of the impact of PV on the distribution system; all prospective installations could then be screened and only the ones requiring more detailed assessment would be floated up to the utilities. This would help preserve low installation costs while allowing for the more detailed assessment that would be necessary at higher penetration levels of distributed PV.

- Develop functional requirements for a communication infrastructure that will enable coordinated operation of all equipment on the distribution feeder. The same infrastructure can be used to enable demand-side management, the implementation of flexible metering tariffs, and enhanced distribution system management.

- Fund demonstration opportunities that illustrate feeder operation with significant PV penetration. 


\subsection{References}

1. "The Potential of Solar PV in Ontario", Rob McMonagle, The Canadian Solar Industries Association, January 30, 2006

2. "Electric Power Distribution Handbook", Tom Short

3. "Power Distribution Planning Reference Book", H. Lee Willis

4. "Reliable, Low Cost Distributed Generator/Utility System Interconnect, 2001 Annual Report”, GE Corporate Research and Development, August 2003, NREL/SR-560-

5. "Study of the Impact of PV Generation on Voltage Profile in LV Distribution Networks", S. Conti, et. al., IEEE Porto Power Tech Conference, September, 2001, Porto, Portugal

6. "IEEE Standard for Interconnecting Distributed Resources with Electric Power Systems", IEEE 1547 Standard, 2003.

7. "IEEE-1547 Comments", Idaho Power Company, Oregon PUC Technical Workshop, Oct. 2006, http://www.puc.state.or.us/PUC/admin_rules/workshops/interconnection/ipcoct18.pdf

8. "Voltage regulation - Tapping Distributed Energy Resources", John D. Kueck, et. al., Public Utilities Fortnightly, Sept. 2004

9. "Dynamic Voltage Regulation Using Distributed Energy Resources", Yan Xu, et. al., 19th International Conference on Electrical Distribution (CIRED), May 07

10. "PSLF - Power System Analysis Software", http://www.gepower.com/prod_serv/products/utility_software/en/downloads/pslf05.pdf 


\subsection{Glossary}

$\begin{array}{ll}\text { PV } & \text { Photovoltaic } \\ \text { ANSI } & \text { American National Standard Institution } \\ \text { TC } & \text { Tap Changer } \\ \text { SVR } & \text { Step Voltage Regulator } \\ \text { OLTC } & \text { On-Load Tap Changer } \\ \text { VAR } & \text { Reactive Power } \\ \text { S } & \text { Apparent Power (also known as Complex Power) } \\ \text { P } & \text { Active Power (also known as Real Power) } \\ \text { Q } & \text { Reactive Power (also known as Imaginary Power) }\end{array}$




\section{REPORT DOCUMENTATION PAGE}

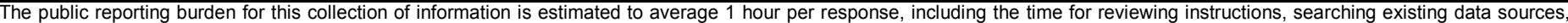

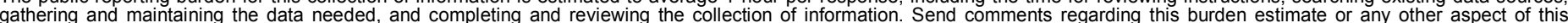

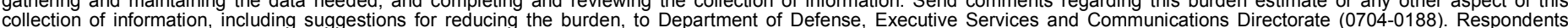

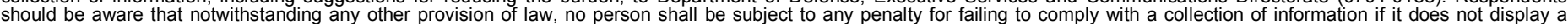

should be aware that notwithstanding

PLEASE DO NOT RETURN YOUR FORM TO THE ABOVE ORGANIZATION.

\begin{tabular}{l|l|l|l} 
1. REPORT DATE $(D D-M M-Y Y Y Y)$ & 2. REPORT TYPE & 3. DATES COVERED (FrOm - TO)
\end{tabular}

February 2008

Subcontract report

4. TITLE AND SUBTITLE

Distribution System Voltage Performance Analysis for High-

Penetration Photovoltaics 5a. CONTRACT NUMBER

DE-AC36-99-G010337

5b. GRANT NUMBER

5c. PROGRAM ELEMENT NUMBER

5d. PROJECT NUMBER

NREL/SR-581-42298

5e. TASK NUMBER

PVB7.6401

5f. WORK UNIT NUMBER

7. PERFORMING ORGANIZATION NAME(S) AND ADDRESS(ES)

GE Global Research

1 Research Circle

Niskayuna, NY 12309

9. SPONSORING/MONITORING AGENCY NAME(S) AND ADDRESS(ES)

National Renewable Energy Laboratory

1617 Cole Blvd.

Golden, CO 80401-3393

12. DISTRIBUTION AVAILABILITY STATEMENT

National Technical Information Service

U.S. Department of Commerce

5285 Port Royal Road

Springfield, VA 22161

13. SUPPLEMENTARY NOTES

NREL Technical Monitor: Ben Kroposki

14. ABSTRACT (Maximum 200 Words)

This report examines the performance of commonly used distribution voltage regulation methods under reverse power flow.

\section{SUBJECT TERMS}

distribution system; photovoltaics; PV; voltage regulation; inverters; renewable systems interconnection; GE Global Research; National Renewable Energy Laboratory; NREL

\begin{tabular}{l}
\hline 16. SECURITY CLASSIFICATION OF: \\
\begin{tabular}{|l|l|l|}
\hline a. REPORT & b. ABSTRACT & c. THIS PAGE \\
Unclassified & Unclassified & Unclassified \\
& & \\
\hline
\end{tabular}
\end{tabular}

\begin{tabular}{|c|c|}
\hline $\begin{array}{l}\text { 17. LIMITATION } \\
\text { OF ABSTRACT }\end{array}$ & $\begin{array}{l}\text { 18. NUMBER } \\
\text { OF PAGES }\end{array}$ \\
\hline UL & \\
\hline
\end{tabular}

19a. NAME OF RESPONSIBLE PERSON

19b. TELEPHONE NUMBER (Include area code)
11. SPONSORING/MONITORING AGENCY REPORT NUMBER NREL/SR-581-42298 